\title{
ARTICLE
}

\section{A ligand-independent integrin $\beta 1$ mechanosensory complex guides spindle orientation}

\author{
Nicoletta I. Petridou ${ }^{1} \&$ Paris A. Skourides ${ }^{1}$
}

Control of spindle orientation is a fundamental process for embryonic development, morphogenesis and tissue homeostasis, while defects are associated with tumorigenesis and other diseases. Force sensing is one of the mechanisms through which division orientation is determined. Here we show that integrin $\beta 1$ plays a critical role in this process, becoming activated at the lateral regions of the cell cortex in a ligand-independent manner. This activation is force dependent and polar, correlating with the spindle capture sites. Inhibition of integrin $\beta 1$ activation on the cortex and disruption of its asymmetric distribution leads to spindle misorientation, even when cell adhesion is $\beta 1$ independent. Examining downstream targets reveals that a cortical mechanosensory complex forms on active $\beta 1$, and regulates spindle orientation irrespective of cell context. We propose that ligand-independent integrin $\beta 1$ activation is a conserved mechanism that allows cell responses to external stimuli.

\footnotetext{
${ }^{1}$ Department of Biological Sciences, University of Cyprus, University Ave 1, New Campus, Nicosia 2109, Cyprus. Correspondence and requests for materials should be addressed to P.A.S. (email: skourip@ucy.ac.cy).
} 
S pindle orientation is a fundamental process in all multicellular organisms important in both symmetrically and asymmetrically dividing cells. During asymmetric divisions, the spindle aligns parallel to a polarity axis so that cell fate determinants are asymmetrically inherited determining cell fate. In symmetric divisions like those of epithelial cells, the spindle is typically oriented parallel to the plane of the tissue, guiding tissue elongation, organ development and maintaining epithelial integrity ${ }^{1,2}$. The positioning and orientation of the mitotic spindle are achieved through the capture of astral microtubules (MTs) at discrete regions on the cell cortex via a conserved cortical complex (Gai/LGN/NuMA). The dynein/dynactin motor proteins are recruited at the cortex through interactions with this complex and exert pulling forces on astral MTs to position the spindle between the two capture sites ${ }^{3}$.

One of the more fascinating recent findings is that the spindle can respond to external mechanical forces. Specifically, evidence emerged that adherent cells sense forces transmitted through retraction fibres (RFs) and can dynamically reorient their spindles along force vectors ${ }^{4}$. Work in Zebrafish and Xenopus revealed that the same holds true in embryonic epithelia, where forces are presumably stemming from adherens and tight junctions that transmit tissue level tension 5,6 . However, our understanding of this process is lacking especially with respect to the proteins responsible for sensing such external stimuli.

Recent work from our group begun to unravel the molecular machinery responsible for force sensing in mitotic cells, when we showed that focal adhesion kinase (FAK)-null cells fail to orient their spindle in response to mechanical cues despite forming normal $\mathrm{RFs}^{5}$. FAK is a tyrosine kinase previously shown to be involved in mechanotransduction from integrin-based complexes called focal adhesions $(\mathrm{FAs})^{7-9}$. Integrins, the transmembrane receptors that interact with extracellular matrix (ECM) components, undergo conformational changes on ligand binding that in turn induces the recruitment of interacting proteins and the formation of FAs linking the ECM to the actin cytoskeleton ${ }^{10}$. Integrin $\beta 1$ has been identified as an important regulator of spindle orientation in cultured cells and in tissues, through its role in the maintenance of cell adhesion and the establishment of polarity in epithelia ${ }^{11-18}$. Surprisingly, however, depletion of FAK leads to defects in force sensing and spindle misorientation $^{5,19}$ even in the Xenopus embryonic skin, where cells are not in contact with $\mathrm{ECM}^{20}$.

In this study, we show that integrin $\beta 1$ becomes asymmetrically activated at the lateral cortex of mitotic cells and that both the activation and the asymmetric distribution of active $\beta 1$ are critical for correct spindle orientation. We go on to show that this activation is ligand independent and force dependent. Examination of downstream effectors of integrin signalling revealed that the active forms of the FA proteins FAK, Src and p130Cas become enriched at the lateral cortex of mitotic cells in an integrin $\beta 1$-dependent manner displaying similar asymmetric distributions. Finally, using rescue experiments in FAK- and Cas-null cells, we identify Cas as a regulator of spindle orientation and show that direct interactions of Cas and Src with FAK are critical for spindle orientation not only in adherent cells, but also in vertebrate epithelia.

\section{Results}

Integrin $\beta 1$ is activated at the lateral mitotic cortex. When cells in culture enter mitosis they round up and most of the FAs disassemble; however, cells retain RFs connecting them to the ECM through small adhesive complexes maintained at their terminations ${ }^{5,21}$. RFs have been shown to exert forces on the cell cortex and the mitotic spindle becomes aligned with such forces ${ }^{4}$. We have previously shown that in FAK-null cells RFs form normally, yet the spindle fails to respond to external forces ${ }^{5}$. This suggested that the adhesive complexes at RF terminations may signal to the cell, acting as mechanosensors. Since force application leads to integrin activation ${ }^{22,23}$, we decided to examine the distribution of active integrin $\beta 1$ and asked whether it is enriched at RF terminations. To do so, we compared the distributions of active and total integrin $\beta 1$ in HeLa cells, using two well-characterized antibodies, HUTS-21 (refs 24,25) and AIIB2 (ref. 26), respectively. As shown, in interphase cells $\beta 1$ is distributed uniformly throughout the cortex and in FA-like structures, while active $\beta 1$ is found almost exclusively at FAs and is excluded from the lateral cortex (Fig. 1a,c). In mitotic cells, although $\beta 1$ is distributed uniformly throughout the cell cortex and RFs, no enrichment of active $\beta 1$ could be detected on RFs suggesting that the adhesive complexes act as mechanical anchoring points (Fig. 1b, yellow arrowheads). Surprisingly, we noted that active $\beta 1$ is enriched at the lateral regions of the cell cortex at the plane of the spindle, a region not in contact with the substrate (Fig. 1b,d, white arrowheads), while it is absent from apical areas displaying strong apicobasal polarity (Fig. 1b,d,e magenta arrowheads). Activation of $\beta 1$ at the cortex of mitotic cells was verified using an alternative combination of antibodies (Supplementary Fig. 1a,b) (refs 27-29).

In addition to the apicobasal polarity, integrin $\beta 1$ activation was also polar at the plane of the spindle (Fig. 1b, white arrowheads). Live immunostaining of active integrin $\beta 1$ gave a clearer signal with lower background making the polarity more pronounced. As shown, active $\beta 1$ at the lateral regions of the cortex is distributed asymmetrically in metaphase cells with a polarity crescent accumulating at regions distal to the spindle poles (Fig. 2a). Furthermore, live immunostaining of active $\beta 1$ in cells expressing green fluorescent protein (GFP)-leucine-glycine-asparagine repeat protein (LGN) showed that the localizations of LGN and active $\beta 1$ are similar. Both display asymmetric distributions, preferentially accumulating at regions distal to the spindle (Fig. 2b, white arrowheads). Enrichment of active $\beta 1$ at the lateral region of the cortex suggested that the distribution of active $\beta 1$ may be determined by the distribution of RFs. High-resolution optical sections of live metaphase cells revealed a close association of RF terminations with active $\beta 1$ and confirmed a correlation with the distribution of RFs. As shown, $\beta 1$ displays the highest activation at areas where the RFs terminate on the cortex (Fig. 2c), a finding confirmed by staining fixed cells (Supplementary Fig. 2).

Overall, these data suggest that integrin $\beta 1$ becomes asymmetrically activated at the lateral cortex during mitosis correlating with the distribution of RFs around the cell cortex.

Integrin $\beta 1$ activation on the cortex depends on RFs. Evidence has emerged that integrin $\beta 1$ can be activated through membrane tension suggesting that the activation at the lateral regions of mitotic cells, which are not in contact with the ECM, may be elicited through RF-derived forces ${ }^{4,23}$. To test this possibility we stained active $\beta 1$ in cells adhering on L-fibronectin (FN) microprints, where the areas of the cell receiving maximal force are predetermined ${ }^{30,31}$. While in interphase, active $\beta 1$ is found exclusively on FAs at the interface between the L-FN and the cell, with undetectable lateral cortical staining, during mitosis active $\beta 1$ becomes enriched at the areas of the cortex that receive the strongest forces (Fig. 3a, white arrowheads) suggesting that force distribution determines the distribution of active $\beta 1$.

We went on to directly address if integrin $\beta 1$ can be activated in ECM-free areas in response to force. Paramagnetic beads coated with E-cadherin-Fc were seeded on E-cadherin-expressing cells, allowed to form adherens junctions (AJs) in the absence of serum and were then pulled with a magnet. As shown in Fig. 3b, 
a Interphase $\quad$ Active integrin $\beta 1 /$ total integrin $\beta 1$

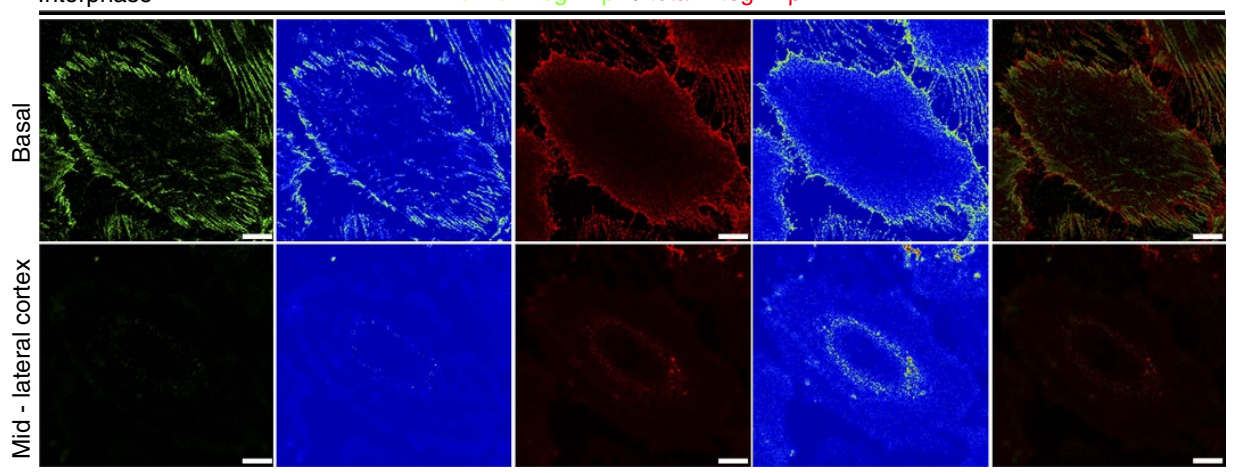

b Metaphase DNA / active integrin $\beta 1 /$ total integrin $\beta 1$
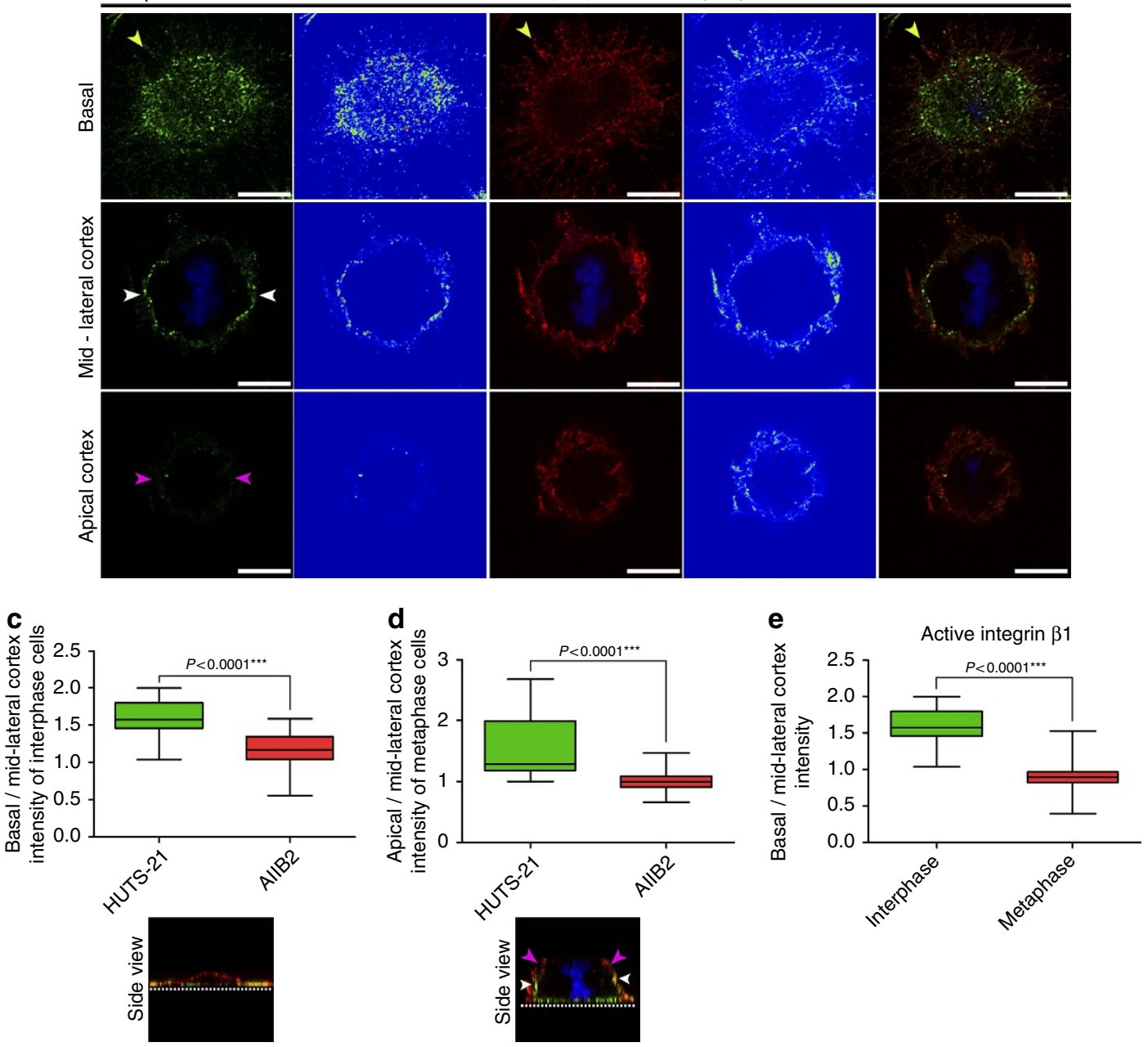

Figure 1 | Integrin $\boldsymbol{\beta 1}$ becomes activated at the lateral cortex of mitotic cells. (a) Representative optical sections, intensity-coded and merged images at the cell-ECM interface and the lateral cortex of interphase HeLa cells stained for active (HUTS-21) and total (AllB2) integrin $\beta 1$. (b) Representative optical sections, colour intensity-coded and merged images at the cell-ECM interface, mid-lateral and apical areas of the cortex of metaphase cells stained as indicated. Yellow arrowheads show integrin $\beta 1$-positive RFs. White arrowheads indicate active $\beta 1$ at the lateral cortex at the plane of the spindle. Magenta arrowheads show absence of active $\beta 1$ from the apical cortex. (c) Box-plot of the basal to mid-lateral cortex intensity ratio of active and total integrin $\beta 1$ in interphase cells and a side view of the cell shown in a (dashed line shows the ECM). Mean \pm s.e.m.: HUTS-21 1.572 $\pm 0.05921, n=20 ; A l l B 2$ $1.158 \pm 0.05203, n=20 ; P$ values calculated by $t$-test; $n$, number of interphase cells, two independent experiments (one-way analysis of variance (ANOVA) for variability between replicates: HUTS-21 $P=0.0643 \mathrm{~ns}$, AllB2 $P=0.1955 \mathrm{~ns}$ ). (d) Box-plot of the mid-lateral to apical cortex intensity ratio of active and total integrin $\beta 1$ in metaphase cells and a side view of the cell shown in $\mathbf{b}$ (dashed line represents the ECM, white arrowheads indicate integrin $\beta 1$ activation at the lateral cortex, magenta arrowheads show absence of active $\beta 1$ at the apical areas of the cortex). Mean \pm s.e.m.: HUTS-21 1.523 $\pm 0.1099, n=20$; AlIB2 $1.010 \pm 0.03892, n=20 ; P$ values calculated by $t$-test; $n$, number of metaphase cells, two independent experiments (one-way ANOVA: HUTS-21 $P=0.5479 \mathrm{~ns}$, AllB2 p-0.2055 ns). (e) Box-plot of the basal to mid-lateral cortex intensity ratio of active integrin $\beta 1$ in interphase and metaphase cells. Mean \pm s.e.m.: interphase $1.572 \pm 0.05921, n=20$; metaphase $0.8887 \pm 0.04829, n=20 ; P$ values calculated by Mann-Whitney test; $n$, number of cells, two independent experiments (Kruskal-Wallis: interphase $P=0.0643 \mathrm{~ns}$, metaphase $P=0.2879 \mathrm{~ns}$ ). Scale bar, $10 \mu \mathrm{m}(\mathbf{a}, \mathbf{b})$. 
a

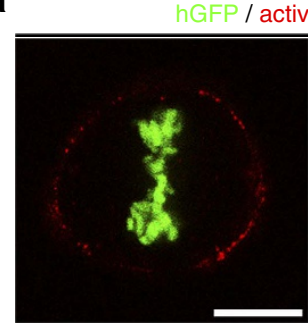

active integrin $\beta 1$

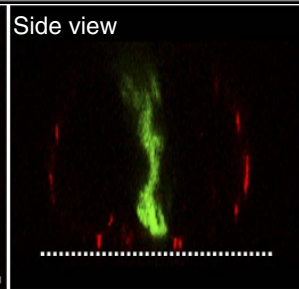

b
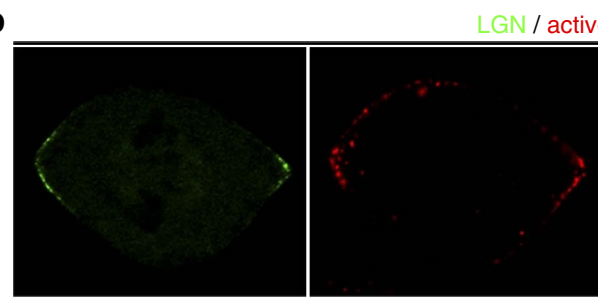

Active integrin $\beta 1$
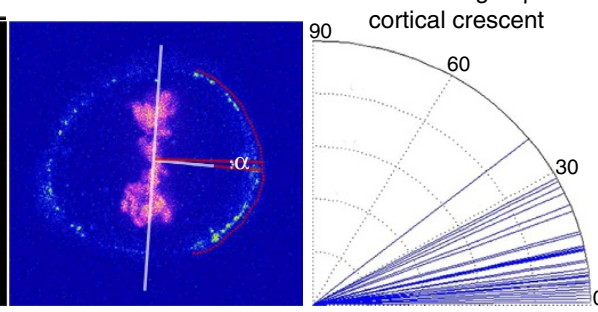

C
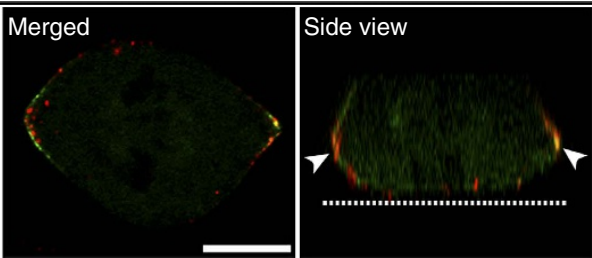

GFP-Utrophin / active integrin $\beta 1$
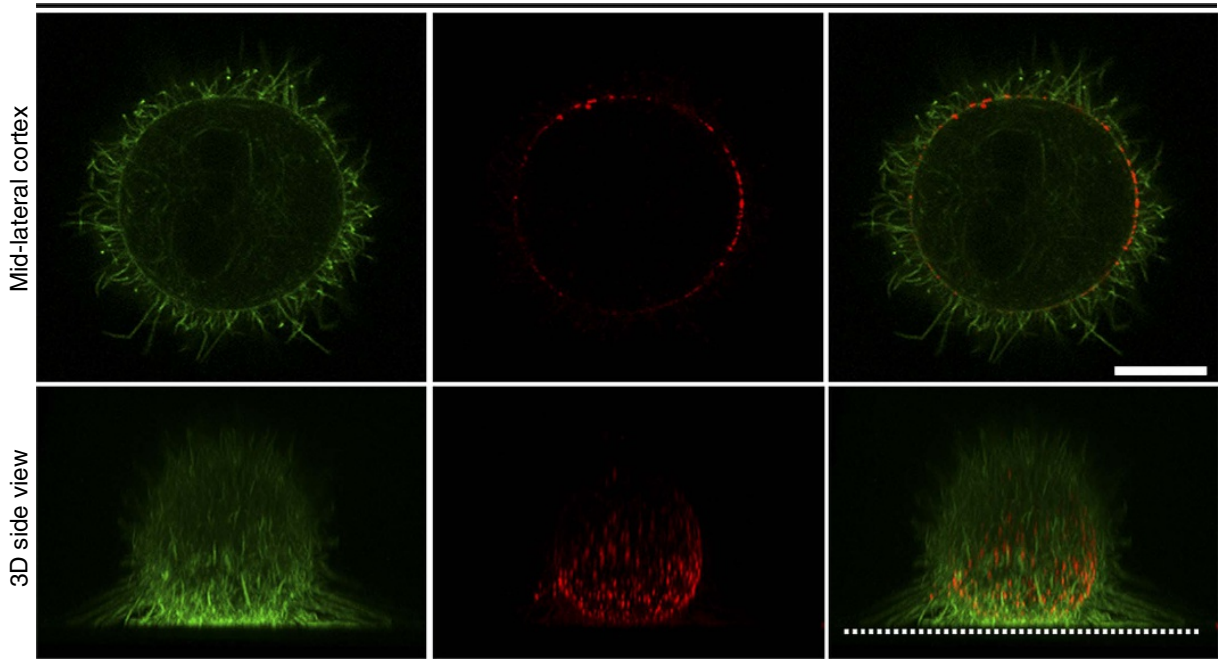

Figure 2 | Active integrin $\boldsymbol{\beta 1}$ is distributed asymmetrically at the lateral cortex of mitotic cells. (a) A representative optical section and a side view of a live metaphase cell expressing histone GFP and stained for active integrin $\beta 1$ (9EG7). Colour intensity image showing how the polarity crescent of active $\beta 1$ was correlated with the spindle capture sites and an angular distribution plot of the angle $\alpha ;$ mean $\pm \mathrm{s}$.e.m.: $11.34 \pm 1.55^{\circ}$, $n=35$; $n$, number of metaphase cells, two independent experiments (two replicates each). (b) Labelling of active $\beta 1$ in live metaphase cells expressing GFP-LGN and a side view showing active $\beta 1$ at the cell-ECM interface and co-localization with LGN at the lateral cortex of the cell (white arrowheads). (c) Optical section at the mid-lateral cortex and a side view of a 3D reconstruction of a representative live metaphase cell expressing GFP-Utrophin stained for active $\beta 1$ (9EG7) showing integrin activation at the areas where the RFs merge with the cell cortex. Scale bar, $10 \mu \mathrm{m}(\mathbf{a}-\mathbf{c})$.

AJs are formed between the cell and the bead but no active integrin $\beta 1$ can be detected around the bead. However, on force application, integrin $\beta 1$ becomes activated on the entire apical cell surface demonstrating that external force is sufficient to activate integrin $\beta 1$ in the absence of a ligand (Fig. 3b,c). This suggests that the observed $\beta 1$ activation at the cortex of mitotic cells is force driven.

However, the correlation of active $\beta 1$ with the spindle capture sites suggests that these forces could be extrinsic through the RFs or intrinsic through the pulling of astral MTs. To discriminate between these two possibilities, we treated cells either with low-dose nocodazole (NZ) to depolymerize astral MTs ${ }^{32}$ or with cytochalasin D (Cyto D) to disrupt the RFs. Although NZ treatment led to spindle misorientation, there was no effect on $\beta 1$ activation (Fig. 3d-f) confirmed by the lack of a correlation between the degree of spindle misorientation and the ratio of basal-to-lateral active $\beta 1$ cortical intensity (Fig. $3 \mathrm{~g}$ ). Moreover, $\mathrm{NZ}$ treatment of cells on L-FN had no effect on the asymmetric distribution of active $\beta 1$ (Supplementary Fig. 3a). These results preclude the possibility that integrin $\beta 1$ activation at the sites of spindle capture is a consequence of the pulling forces from astral MTs. In contrast, Cyto D treatment led to spindle misorientation and nearly eliminated $\beta 1$ activation on the cortex (Fig. 3d-f, Supplementary Fig. 3a). Importantly, the degree of spindle misorientation was positively correlated with the change of cortex intensity of active $\beta 1$ linking cortical $\beta 1$ activation to spindle orientation (Fig. 3g). Cyto D treatment, however, had a visible effect on cortical actin. To ensure that loss of active $\beta 1$ is not an indirect effect of the disruption of the actin network, we seeded cells on poly-L-lysine (PLL), a substrate on which cells fail to form FAs and RFs ${ }^{33}$. Cells seeded on PLL displayed spindle misorientation and lack of cortical $\beta 1$ activation, confirming that activation of $\beta 1$ on the lateral cortex during mitosis depends on $\mathrm{RFs}^{12}$ (Supplementary Fig. 3b-d). Overall, these data suggest that integrin $\beta 1$ can become activated in response to external force and that during mitosis integrin $\beta 1$ activation depends on RFs. 
a

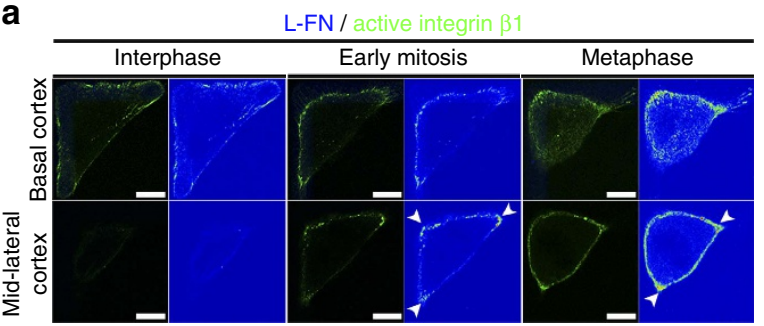

b

Phalloidin / $\beta$-catenin / active integrin $\beta 1$

C
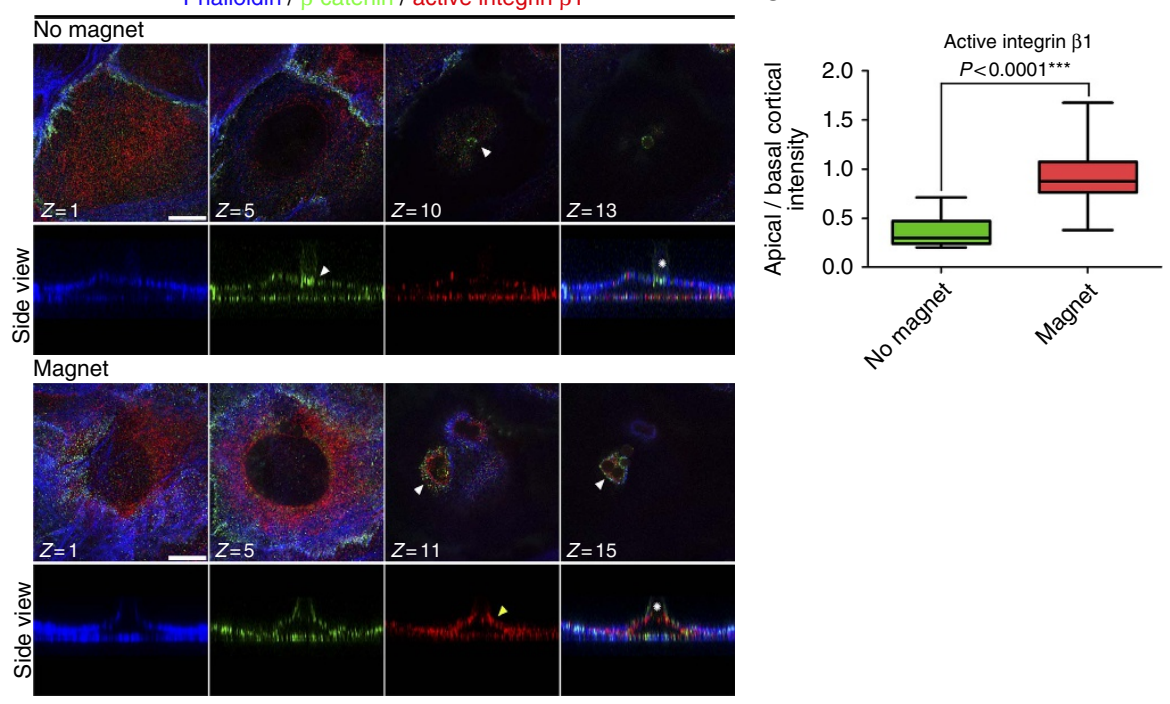

d

Phalloidin / $\beta$-tubulin / active integrin $\beta 1$

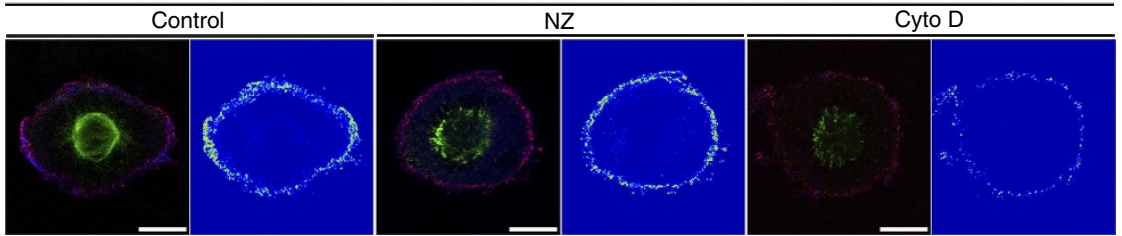

e
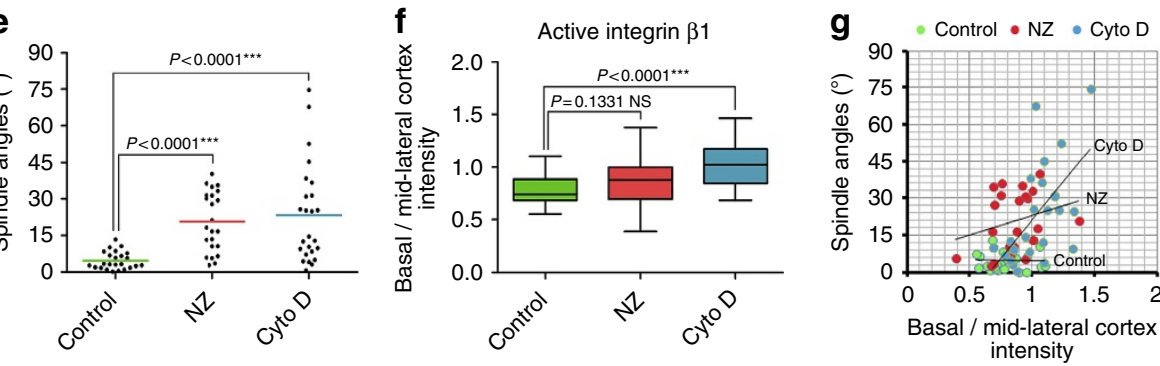

Figure 3 | Force-dependent activation of cortical integrin $\beta 1$. (a) Optical sections and colour intensity-coded images at the cell-ECM interface and mid-lateral cortex of interphase, early mitotic and metaphase cells seeded on L-FN microprints. Arrowheads indicate areas where maximal forces are exerted. (b) Z-stacks and side view of MCF10A cells with attached E-cadherin-coated beads (asterisk) on their apical surface in the absence or presence of a magnet, imaged under the same conditions. The white arrowhead shows AJs formation between the apical surface and the bead. The yellow arrowhead shows $\beta 1$ activation at apical surface on force application. (c) Box-plot of the apical to basal cortex intensity ratio of active $\beta 1$ in the presence or absence of force. Mean \pm s.e.m.: no magnet $0.3745 \pm 0.03963, n=17$; magnet $0.9211 \pm 0.06990, n=20 ; P$ values calculated by $t$-test; $n$, number of cells, three independent experiments (one-way analysis of variance: no magnet $P=0.8469 \mathrm{~ns}$, magnet $P=0.5004 \mathrm{~ns}$ ). (d) Optical sections at the plane of the spindle and colour intensity-coded image of control, NZ or Cyto D-treated cells, imaged under the same conditions. (e) Scatter plot of substrate to spindle angles of the cells in d. Mean \pm s.e.m.: control $4.696 \pm 0.7338^{\circ}, n=24$; NZ $20.60 \pm 2.527^{\circ}, n=23$; Cyto D $23.20 \pm 4.037^{\circ}, n=25 ; P$ values calculated by Mann-Whitney test; $n$, number of metaphase cells, two independent experiments (Kruskal-Wallis: Control $P=0.1615 \mathrm{~ns}, \mathrm{NZ} P=0.6323 \mathrm{~ns}, \mathrm{Cyto} D$ $P=0.4075 \mathrm{~ns}$ ). (f) Box-plot of the basal to mid-lateral cortex intensity ratio of active integrin $\beta 1$ of the cells analysed in e. Mean \pm s.e.m.: control $0.7807 \pm 0.03210, n=24 ; \mathrm{NZ} 0.8597 \pm 0.04068, n=23$; Cyto D $1.030 \pm 0.03908, n=25 ; P$ values calculated by $t$-test; $n$, number of metaphase cells, two independent experiments (one-way analysis of variance: control $P=0.2332 \mathrm{~ns}$, NZ $P=0.1480 \mathrm{~ns}$, Cyto $D P=0.7993 \mathrm{~ns}$ ). (g) Correlation of the degree of spindle misorientation with the ratio of basal to mid-lateral cortex intensity of active $\beta 1$. Pearson's correlation coefficients: control $r=-0.0289$, weak correlation, NZ $r=0.2547$ weak correlation, Cyto D $r=0.5919$ moderate positive correlation. Scale bar, $10 \mu \mathrm{m}(\mathbf{a}, \mathbf{b}, \mathbf{d})$. 
Cortically polarized active $\beta 1$ guides spindle orientation. Given the RF-dependent polar activation of integrin $\beta 1$ at the cortex of mitotic cells and its correlation with spindle orientation we wanted to explore the possibility that this activation has a direct role in spindle orientation. To do so, we had to block ligand unoccupied integrin $\beta 1$ on the lateral cortex without affecting ligand bound $\beta 1$ at the cell-ECM interface. We took advantage of the $\beta 1$-blocking antibody $\mathrm{P} 4 \mathrm{C} 10$, which has been shown to preferentially bind unoccupied integrin $\beta 1$ (refs 34,35 ). This antibody would presumably selectively inactivate the cortical pool of $\beta 1$, which is not ligand bound, whereas engaged integrins at the cell-ECM interface would be unaffected. In agreement with the above, treatment of cells seeded on FN with P4C10, resulted in the reduction of active $\beta 1$ on the mitotic cortex, while cell adhesion was unaffected (Fig. 4a,c, Supplementary Fig. 4a). Loss of active $\beta 1$ from the lateral areas of the cortex led to spindle misorientation and the degree of misorientation correlated with the loss of active $\beta 1$ (Fig. 4b,d). Although these data suggest that activation of $\beta 1$ on the lateral cortex is necessary for spindle orientation, effects of the antibody on adhesive complexes at the RF-FN interface cannot be ruled out. To address this, we took advantage of cell adhesion to vitronectin (VN). VN interacts with cells through its RGD integrin-binding sequence; however, cell attachment does not depend exclusively on $\beta 1$ as in the case of adhesion to $\mathrm{FN}^{36}$. Moreover, multiple cell types including HeLa cells were shown to also rely on uPAR for adhesion to $\mathrm{VN}$ and inhibition of integrin-dependent adhesion on $\mathrm{VN}$ does not eliminate cell attachment ${ }^{37}$. As shown, total and active $\beta 1$ are nearly absent from FAs when cells are seeded on VN (Supplementary Fig. 4b-d). Despite the near undetectable levels of active $\beta 1$ in interphase cells, cortical activation of $\beta 1$ in mitotic cells on $\mathrm{VN}$ is unaffected and spindles are oriented (Fig. $4 \mathrm{a}-\mathrm{c}$ ). Treatment of cells seeded on VN with P4C10 resulted in loss of cortically active $\beta 1$ and elicited spindle misorientation despite a lack of any effect on cell adhesion (Fig. 4a-d, Supplementary Fig. 4a). This result confirms that even when cell adhesion is $\beta 1$-independent, $\beta 1$ activation on the cortex is necessary for correct spindle orientation.

Given the importance of integrin $\beta 1$ cortical activation in spindle orientation, we then asked whether the asymmetric distribution of active $\beta 1$ is important. We postulated that if $\beta 1$ has a role in determining the capture sites of astral MTs, then integrin $\beta 1$ overactivation would lead to spindle misorientation. Treatment of cells with RGD peptide at concentrations that disrupt integrin-dependent adhesion via competition for binding to the substrate has been shown to lead to spindle misorientation ${ }^{12}$. We postulated that treatment of cells adhering on FN with low concentrations of RGD would fail to compete with immobilized FN on the cell's basal region and thus not disrupt adhesion, but bind to and activate unoccupied cortically localized integrins. We found that at $50 \mu \mathrm{g} \mathrm{ml}^{-1}, \mathrm{RGD}$ did not perturb cell adhesion (Supplementary Fig. $5 \mathrm{a}-\mathrm{c}$ ) or RF formation (Fig. 5a,c). Although at this concentration RGD treatment failed to activate $\beta 1$ in interphase cells, it elicited robust activation throughout the cortex in mitotic cells (Fig. 5b,e, yellow arrowheads), presumably due to the higher overall membrane tension displayed by such cells ${ }^{38}$, leading to spindle misorientation (Fig. 5a,d). This suggests that the polar distribution of active $\beta 1$ in mitotic cells is required for correct spindle orientation. To preclude the possibility that undetectable effects of RGD on cell adhesion were responsible, a second approach was implemented where very low concentrations of RGD were combined with an activating integrin antibody (9EG7) which stimulates adhesion. Treatment with 9EG7 was not sufficient to induce ectopic integrin $\beta 1$ activation because the epitope recognized by 9EG7 is exposed when $\beta 1$ is bound to a ligand $^{28}$. We thus pretreated cells with lower concentrations of RGD $\left(10 \mu \mathrm{g} \mathrm{ml}^{-1}\right)$ to expose the 9EG7 epitope and then incubated cells with 9EG7 so that 'primed' integrin molecules can be fully activated. Treatment of cells with $10 \mu \mathrm{g} \mathrm{ml}^{-1} \mathrm{RGD}$ peptide had no effect on cell adhesion, spindle orientation, RF formation or integrin activation even in mitotic cells. However, in RGD + 9EG7-treated cells, $\beta 1$ was activated throughout the mitotic cortex and spindles were misoriented despite normal $\mathrm{RF}$ formation and cell adhesion (Fig. 5a-e, Supplementary Fig. $5 a-c)$.

Overall, the above data show that both the activation and the asymmetric distribution of active $\beta 1$ on the cortex are required for correct spindle orientation suggesting that the cortical pool of active $\beta 1$ is directly involved in spindle orientation.

Ligand-independent $\beta 1$ activation guides spindle orientation. The above data collectively suggest that integrin $\beta 1$ becomes activated in the absence of ligand and guides spindle orientation. To address directly whether force application is sufficient to activate integrin $\beta 1$ on the cell cortex independently of ligand binding and influence spindle orientation, we applied external force on mitotic cells using E-cadherin-coated paramagnetic beads as described in Fig. 3b. Cells were either fixed directly or after placing a magnet above them for $30 \mathrm{~min}$. As shown in Fig. 6a, in the absence of external force the mitotic spindle is oriented properly parallel to the substrate and active $\beta 1$ is primarily enriched at the mid-lateral cortex. However, on force application integrin $\beta 1$ becomes activated throughout the cell cortex and the orientation of the mitotic spindle becomes randomized (Fig. 6a-c), showing that application of force perpendicular to the substrate plane leads to ectopic $\beta 1$ activation on the apical cortex eliciting reorientation of the spindle.

To address directly whether $\beta 1$ activation at the mid-lateral cortex is ligand independent, we seeded E-cadherin expressing cells in an integrin-independent manner and examined whether $\beta 1$ becomes activated at the lateral cortex during mitosis. Cells were seeded on E-cadherin-Fc immobilized on silanized glass ${ }^{39}$ in the absence of serum and allowed to attach for $2 \mathrm{~h}$. As previously described $^{40,41}$, the cells attached through the generation of AJs on this substrate (Fig. 6d). Under these conditions the cells formed no detectable FAs and no active integrin $\beta 1$ could be detected in interphase cells, while $\beta$-catenin-positive adhesions were free of active $\beta 1$ (Fig. 6d). However, active $\beta 1$ was readily detected in mitotic cells at the lateral cortex, and enriched at the spindle capture sites but excluded from the basal surface (Fig. 6e). These results confirm that integrin $\beta 1$ is activated in a ligand-independent manner in mitotic cells.

Previous work revealed that FAK, a major downstream effector of integrins, is required for correct spindle orientation in the Xenopus outermost epithelium, a tissue where cells orient their spindles in an ECM-independent manner ${ }^{5,20}$. The outer epithelial cells of Xenopus are not in contact with the ECM and do not form FAs or RFs. This tissue consists of two cell layers attached through AJs so the outer layer, as shown (Fig. 6f), is never directly in contact with the $\mathrm{ECM}^{20,42}$. Nevertheless, integrin $\beta 1$ is expressed in the outer cells localizing at their basolateral region (Fig. $6 \mathrm{~g}$ ). To address a possible role of $\beta 1$ in spindle orientation in this tissue we expressed a previously characterized dominant-negative ${ }^{20,43}$. As shown, blocking integrin $\beta 1$ function leads to spindle misorientation suggesting a conserved ligand-independent role of $\beta 1$ in spindle orientation in embryonic tissues (Fig. 6h).

Taken together, these results suggest that during mitosis integrin $\beta 1$ regulates spindle orientation in response to external forces in a ligand-independent manner. 
a

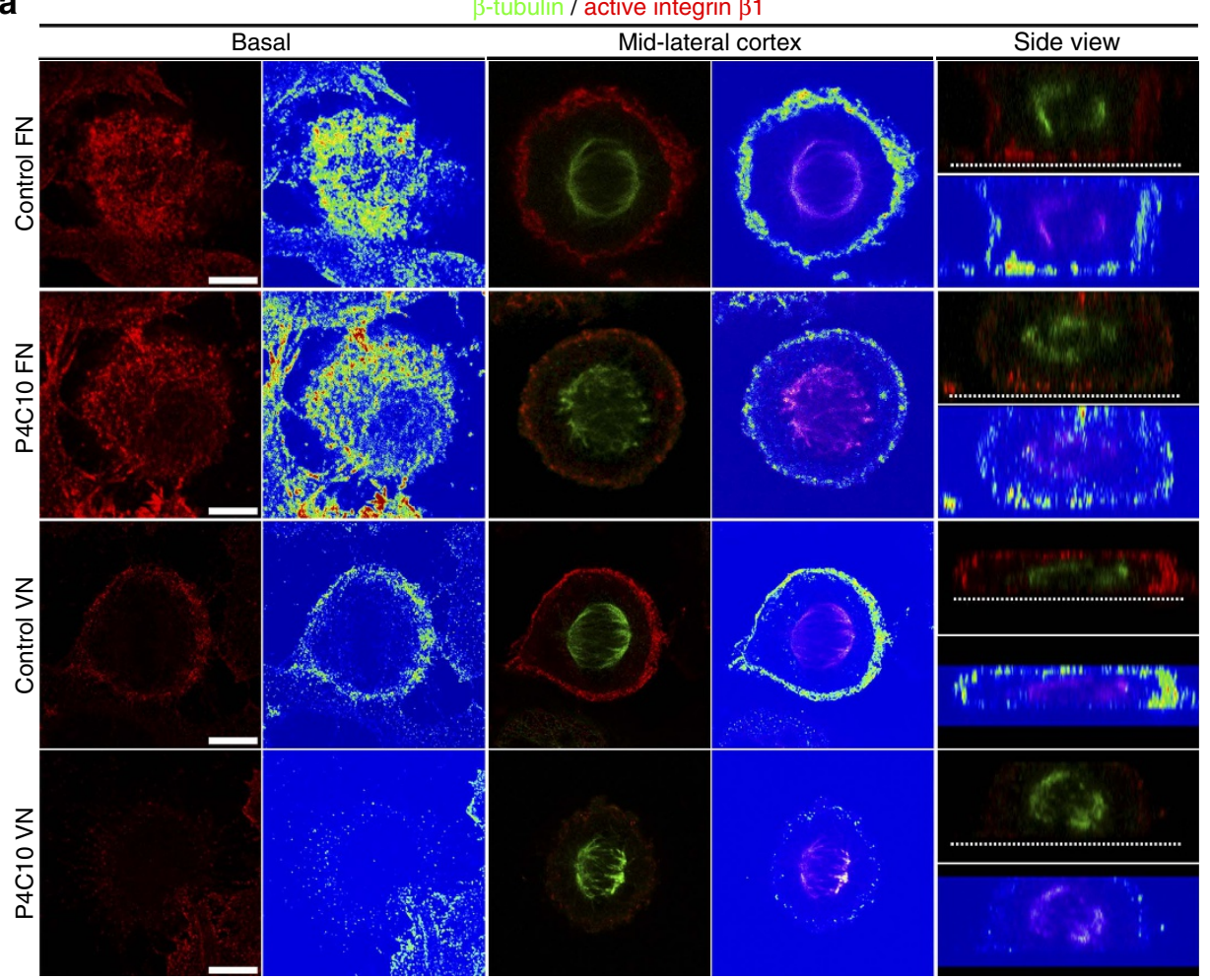

b

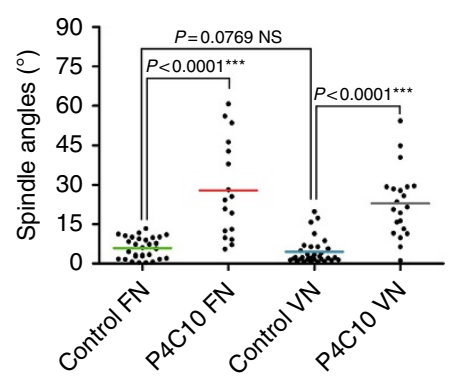

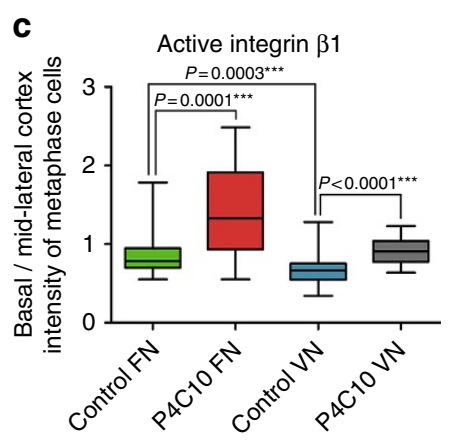

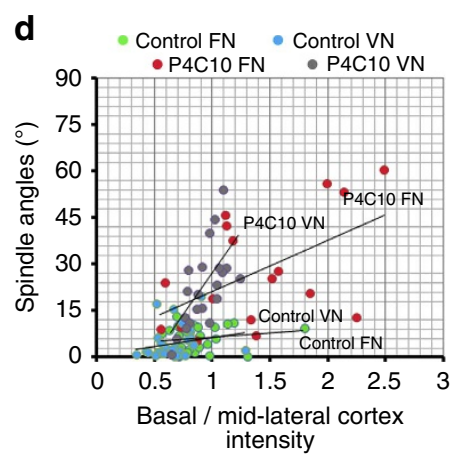

Figure 4 | Inhibition of integrin $\boldsymbol{\beta 1}$ cortical activation leads to spindle misorientation. (a) Optical sections at the cell-ECM interface and at the spindle plane, colour intensity-coded images and side views of representative metaphase control or P4C10 antibody-treated HeLa cells seeded on FN or VN. All cells were imaged under the same conditions. Cells were stained with $\beta$-tubulin and 9EG7 antibodies. The dashed lines show the cell-ECM interface. (b) Scatter plot of substrate to spindle angles of metaphase cells from the above conditions. Mean \pm s.e.m.: Control FN $5.920 \pm 0.7391^{\circ}, n=30 ; \mathrm{P} 4 \mathrm{C} 10 \mathrm{FN}$ $27.76 \pm 4.455^{\circ}, n=17$; Control VN 4.427 $\pm 0.8606^{\circ}, n=33$; P4C10 VN $22.84 \pm 2.824^{\circ}, n=21 ; P$ values calculated by Mann-Whitney test; $n$, number of metaphase cells, two independent experiments (Kruskal-Wallis: control FN $P=0.3414 \mathrm{~ns}, \mathrm{P} 4 \mathrm{C} 10 \mathrm{FN} P=0.2055 \mathrm{~ns}$, control VN $P=0.1060 \mathrm{~ns}$, control VN $P=0.6050 \mathrm{~ns}$ ). (c) Box-plot of the basal to mid-lateral cortex intensity ratio of active integrin $\beta 1$ of the cells analysed in (b). Mean \pm s.e.m.: control FN $0.8482 \pm 0.04543, n=30 ;$ P4C10 FN 1.388 $\pm 0.1422, n=17$; control VN $0.6639 \pm 0.02926, n=33 ;$ P4C10 VN $0.9175 \pm 0.03423, n=21 ; P$ values calculated by Mann-Whitney test; $n$, number of metaphase cells, two independent experiments (Kruskal-Wallis: control FN $P=0.0852 \mathrm{~ns}$, P4C10 FN $P=0.3592 \mathrm{~ns}$, control VN $P=0.3051 \mathrm{~ns}, \mathrm{P} 4 \mathrm{C} 10 \mathrm{VN} P=0.5787 \mathrm{~ns}$ ). (d) Correlation of the spindle angle and the ratio of basal to mid-lateral cortex intensity of active integrin $\beta 1$. Pearson's correlation coefficient: control FN $r=0.1755$ weak correlation, control VN $r=0.2006$ weak correlation, $\mathrm{P} 4 \mathrm{C} 10 \mathrm{FN} r=0.5601$ moderate positive correlation, $\mathrm{P} 4 \mathrm{C} 10 \mathrm{VN} r=0.645$ moderate positive correlation. Scale bar, $5 \mu \mathrm{m}$ (a).

A mechanosensory complex is formed on the mitotic cortex. We went on to explore the mechanism by which $\beta 1$ activation modulates spindle capture on the cortex. Astral MT capture is achieved through the capture machinery and previous work suggested that cortical accumulation of LGN/NuMA is compromised on loss of the RFs after drug treatments ${ }^{44,45}$. Although this was attributed to a role of actin filaments in the recruitment of LGN/NuMA to the cortex it also raised the possibility that $\beta 1$ activation may influence the cortical recruitment of LGN/NuMA since Cyto $\mathrm{D}$ also eliminated $\beta 1$ activation. To test this possibility, we examined the localization of LGN/NuMA in cells seeded on
PLL that display no $\beta 1$ activation but have an intact actin cytoskeleton. As shown, although cells on PLL display spindle misorientation, the cortical accumulation of LGN and NuMA are unaffected and both are enriched at the regions of the cortex proximal to the spindle poles, marking the spindle capture sites (Supplementary Fig. 6). These results show that the spindlecortex link is unaffected in the absence of $\beta 1$ activation and suggest that integrin $\beta 1$ orients the mitotic spindle though a capture machinery-independent mechanism.

Work by the Humphries group has shown that $\beta 1$ activation at FAs leads to targeting of MTs at the cortex and their stabilization 
a

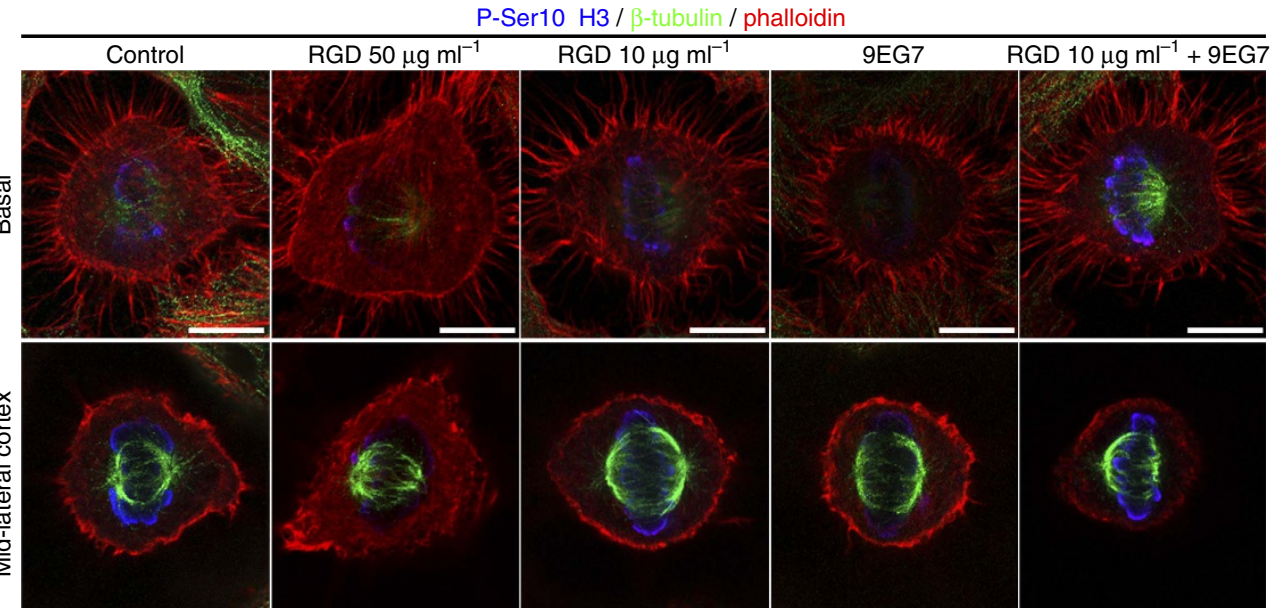

b

Active integrin $\beta 1$
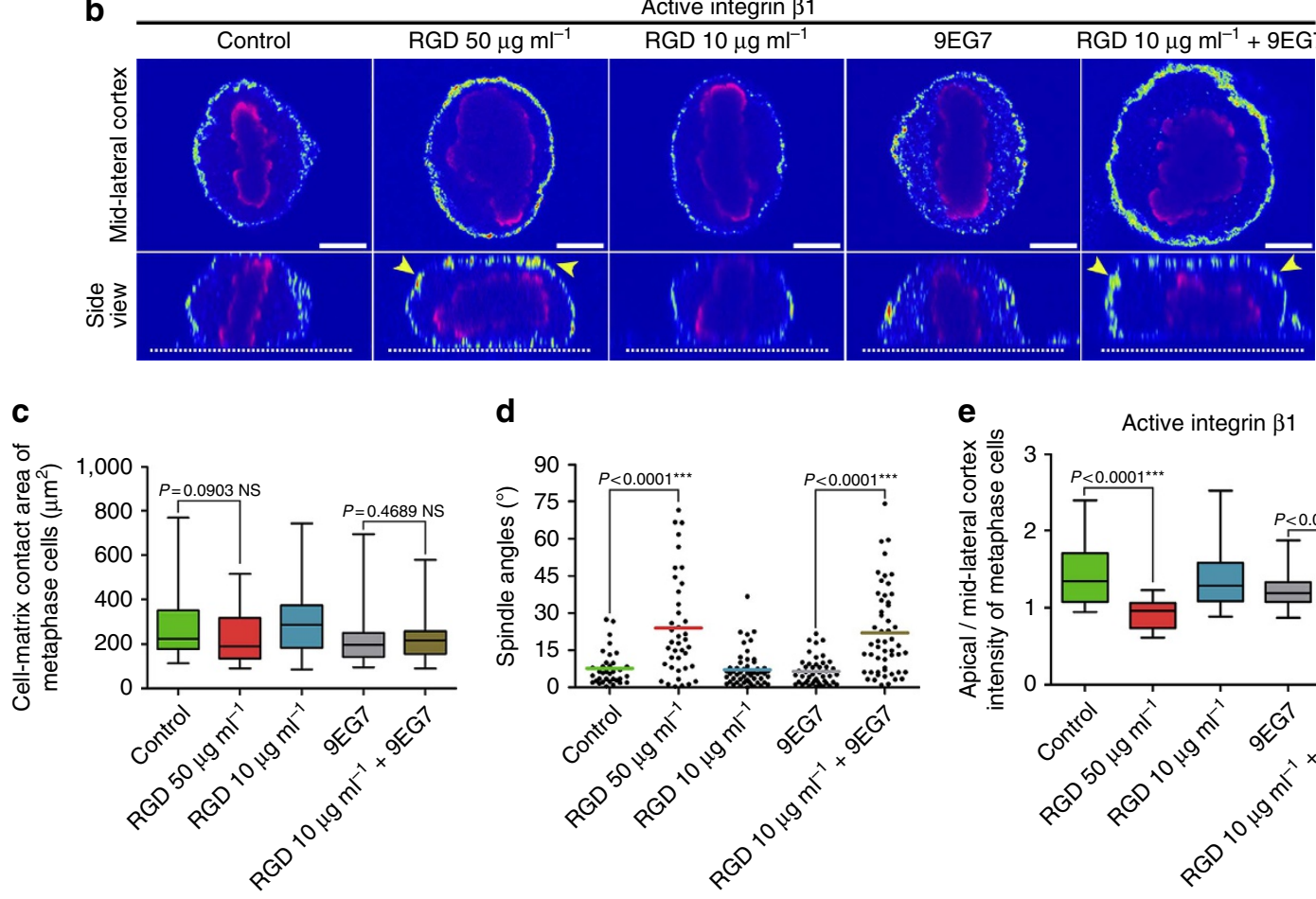

d

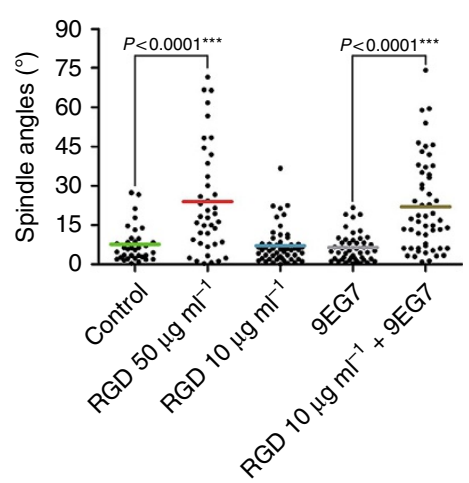

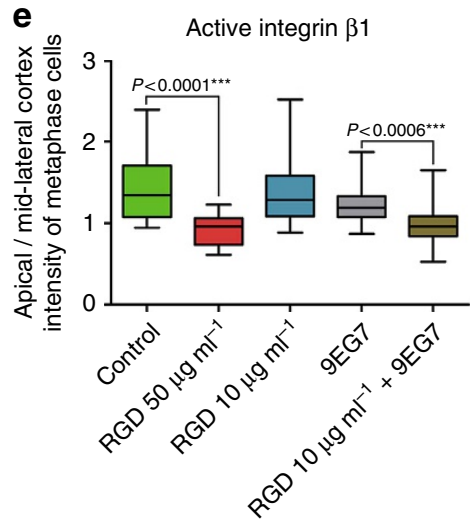

Figure 5 | Disruption of the asymmetric distribution of cortically active $\boldsymbol{\beta 1}$ leads to spindle misorientation. (a) Optical sections at the RF and spindle planes of control and treated metaphase cells with RGD $50 \mu \mathrm{gl}^{-1}$, RGD $10 \mu \mathrm{g} \mathrm{ml}^{-1}$, 9EG7 antibody, RGD $10 \mu \mathrm{g} \mathrm{ml}{ }^{-1}+9 \mathrm{EG7}$ antibody. (b) Colour intensity-coded optical sections at the spindle plane and side views from metaphase cells under the conditions in $\mathbf{a}$. All cells were imaged under the same conditions. The dashed lines show the cell-ECM interface. Yellow arrowheads indicate $\beta 1$ activation throughout the cortex. (c) Box-plot of the cell-matrix contact area. Mean \pm s.e.m.: control $278.4 \pm 24.09 \mu \mathrm{m}^{2}, n=35$; RGD $50 \mu \mathrm{g} \mathrm{ml}{ }^{-1} 235.0 \pm 19.48 \mu \mathrm{m}^{2}, n=40 ; R G D 10 \mu \mathrm{g} \mathrm{ml}{ }^{-1} 298.6 \pm 20.95 \mu \mathrm{m}^{2}, n=54$; 9EG7 225.1 $\pm 18.42 \mu \mathrm{m}^{2}, n=48$; RGD $10 \mu \mathrm{g} \mathrm{ml}^{-1}+9 \mathrm{EG} 7216.5 \pm 11.43 \mu \mathrm{m}^{2}, n=53$; $P$ values calculated by Mann-Whitney test; $n$, number of metaphase cells, three independent experiments (Kruskal-Wallis: control $P=0.0997 \mathrm{~ns}, \mathrm{RGD} 50 \mu \mathrm{g} \mathrm{ml}^{-1} P=0.1880 \mathrm{~ns}, \mathrm{RGD} 10 \mu \mathrm{g} \mathrm{ml}{ }^{-1} P=0.7515 \mathrm{~ns}, 9 \mathrm{EG} 7$ $P=0.1049 \mathrm{~ns}$, RGD $10 \mu \mathrm{g} \mathrm{ml}{ }^{-1}+9 \mathrm{EG} 7 P=0.0557 \mathrm{~ns}$ ). (d) Scatter plot of substrate to spindle angles of cells analysed in c. Mean \pm s.e.m.: control $7.607 \pm 1.163^{\circ}, n=35 ;$ RGD $50 \mu \mathrm{g} \mathrm{ml}^{-1} 23.91 \pm 3.219^{\circ}, n=40 ; \mathrm{RGD} 10 \mu \mathrm{g} \mathrm{ml} \mathrm{l}^{-1} 7.100 \pm 0.9431^{\circ}, n=54 ; 9 \mathrm{EG} 76.385 \pm 0.7696^{\circ}, n=48 ; \mathrm{RGD}$ $10 \mu \mathrm{g} \mathrm{ml}^{-1}+9 \mathrm{EG7} 21.97 \pm 2.408^{\circ}, n=53 ; P$ values calculated by Mann-Whitney test; $n$, number of metaphase cells, three independent experiments (Kruskal-Wallis: control $0.5484 \mathrm{~ns}, \mathrm{RGD} 50 \mu \mathrm{g} \mathrm{ml}{ }^{-1} P=0.5495 \mathrm{~ns}, \mathrm{RGD} 10 \mu \mathrm{g} \mathrm{ml}-1 P=0.6883 \mathrm{~ns}, 9 \mathrm{EG} 7 \mathrm{P}=0.5275 \mathrm{~ns}, \mathrm{RGD} 10 \mu \mathrm{g} \mathrm{ml}-1+9 \mathrm{EG} 7$ $P=0.8523 \mathrm{~ns}$ ). (e) Box-plot of the apical to mid-lateral cortex intensity ratio of the cells in $\mathbf{b}$. Mean \pm s.e.m.: Control 1.438 $\pm 0.09659, n=21$; RGD $50 \mu \mathrm{g} \mathrm{ml}^{-1} 0.9443 \pm 0.04263, n=19 ; \mathrm{RGD} 10 \mu \mathrm{g} \mathrm{ml}^{-1} 1.393 \pm 0.08771, n=20 ; 9 \mathrm{EG} 71.222 \pm 0.04880, n=20 ; \mathrm{RGD}^{10} \mu \mathrm{g} \mathrm{ml}-1+9 \mathrm{EG} 7$ $0.9646 \pm 0.05918, n=19 ; P$ values calculated by Mann-Whitney test; $n$, number of metaphase cells, two independent experiments (Kruskal-Wallis: Control $P=0.9148 \mathrm{~ns}$, RGD $50 \mu \mathrm{g} \mathrm{ml}^{-1} P=0.0777 \mathrm{~ns}, \mathrm{RGD} 10 \mu \mathrm{g} \mathrm{ml} \mathrm{l}^{-1} P=0.5638 \mathrm{~ns}$, 9EG7 $P=0.4708$, RGD $10 \mu \mathrm{g} \mathrm{ml} \mathrm{l}^{-1}+9 \mathrm{EG} 7 P=0.3762 \mathrm{~ns}$ ). Scale bars $10 \mu \mathrm{m}$ (a), $5 \mu \mathrm{m}$ (b).

at this region ${ }^{46}$. This, coupled with our previous findings concerning the role of FAK in spindle responses to external force $^{5}$, raised the possibility that FA-like complexes form in response to $\beta 1$ activation at the cortex preferentially guiding and stabilizing astral MTs towards regions receiving external forces. We began by examining the localization of phosphorylated FAK. Active FAK is localized at FAs in interphase cells ${ }^{47}$, however, during mitosis it is detected on the cell cortex (Fig. 7a). Given 
a

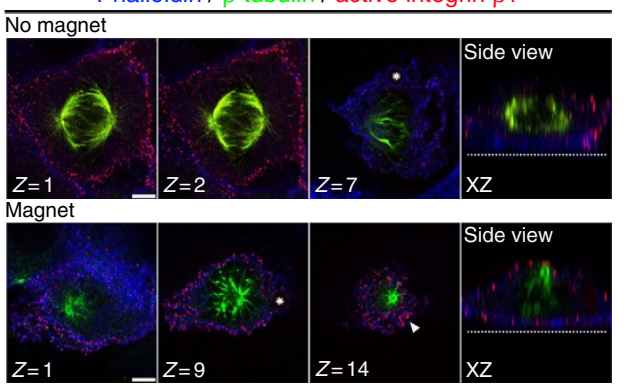

$\mathbf{d}_{\beta \text {-catenin / paxillin / active integrin } \beta 1 \text { E-cad / } \beta \text {-catenin }}$

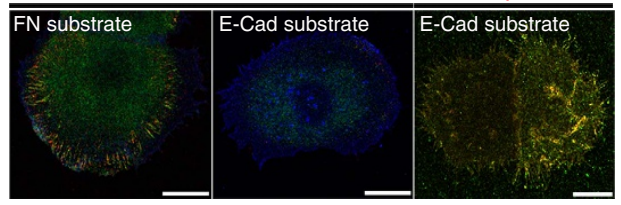

e

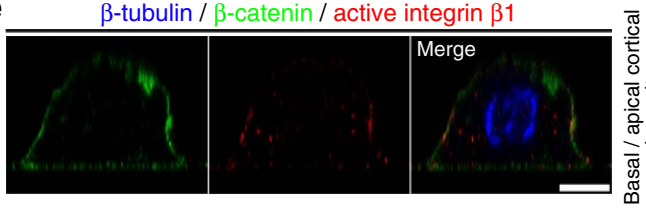

f

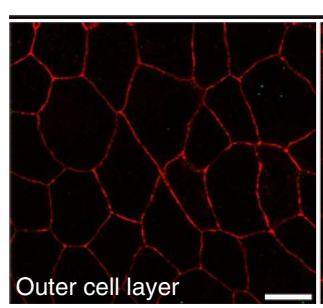

g

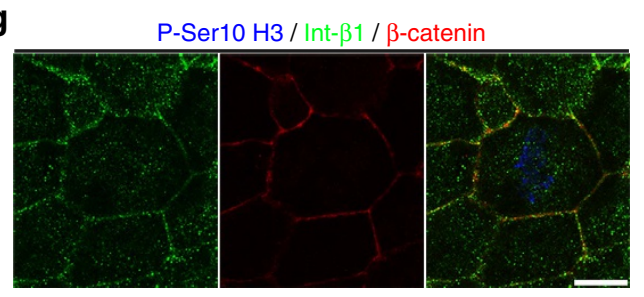

b

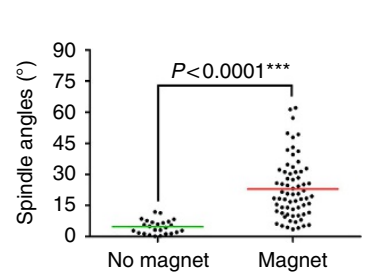

C

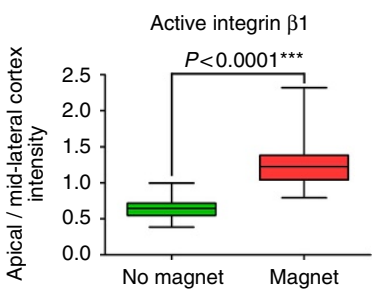

Active integrin $\beta 1$

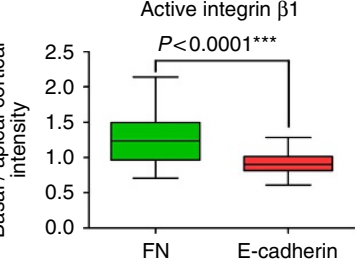

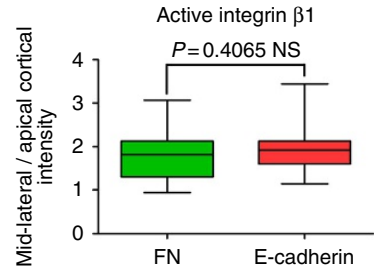

FN / $\beta$-catenin

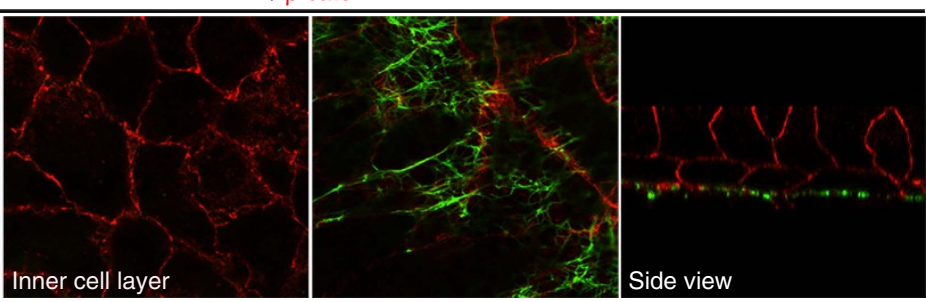

h

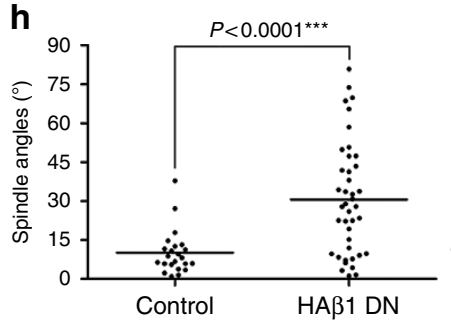

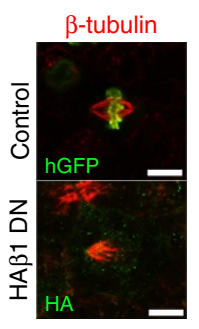

Figure 6 | Force-dependent and ligand-independent activation of integrin $\boldsymbol{\beta 1}$ on the lateral mitotic cortex. (a) Optical sections of MCF10A metaphase cells with attached E-cadherin-coated magnetic beads (asterisk) in the presence or absence of a magnet. The white arrowhead indicates $\beta 1$ activation at the apical surface. (b) Scatter plot of substrate to spindle angles for the cells shown in (a). Mean \pm s.e.m.: no magnet $4.604 \pm 0.6672^{\circ}, n=25$; magnet $22.91 \pm 1.745^{\circ}, n=67$; number of metaphase cells, three independent experiments (Kruskal-Wallis: no magnet $P=0.0963 \mathrm{~ns}$, magnet $P=0.5604 \mathrm{~ns}$ ) (c) Box-plot of the ratio of apical to mid-lateral cortex intensity of active $\beta 1$ for the cells in a. Mean \pm s.e.m.: no magnet $0.6418 \pm 0.02712, n=25$; magnet $1.256 \pm 0.03875, n=67 ; P$ values calculated by Mann-Whitney test; $n$, number of metaphase cells, three independent experiments (Kruskal-Wallis: no magnet $P=0.5099 \mathrm{~ns}$, magnet $P=0.7475 \mathrm{~ns}$ ). (d) Confocal images of MCF10A interphase cells seeded on FN or E-cadherin-Fc-coated silanized coverslips. (e) Side view of an MCF10A metaphase cell seeded on E-cadherin-Fc and box-plots of basal/apical and mid-lateral/apical cortex intensity ratio of active $\beta 1$ on $\mathrm{FN}$ versus $\mathrm{E}$-cadherin substrate. Mean \pm s.e.m.: basal/apical: $F N 1.260 \pm 0.07387, n=21$; $E$-cadherin $0.9181 \pm 0.03399, n=21$; mid-lateral/apical: FN $1.800 \pm 0.1238, n=21$; E-cadherin $1.948 \pm 0.1149, n=21 ; P$ values calculated by Mann-Whitney test; $n$, number of metaphase cells, three independent experiments (Kruskal-Wallis for basal/apical: FN $P=0.4231 \mathrm{~ns}$, E-cadherin $P=0.3451 \mathrm{~ns}$; for mid-lateral/apical: FN $P=0.7960 \mathrm{~ns}$, E-cadherin $P=0.754 \mathrm{~ns}$ ). (f) Optical sections at the Xenopus outermost epithelial layer, innermost epithelial layer, basal surface of the inner epithelial layer and a side view. (g) Optical section at the mid-lateral cortex of a mitotic cell of the Xenopus outermost epithelium. (h) Representative top views of mitotic control cells (histone GFP injected) or cells injected with integrin $\beta 1$ dominant-negative (HA $31-D N$ ) of the Xenopus epidermis and a scatter plot of the apical surface to spindle angles of these cells. Mean \pm s.e.m.: control $10.06 \pm 1.758^{\circ}, n=23 ;$ HA $\beta 1-D N 30.66 \pm 3.389^{\circ}, n=41 ; P$ value analysed by Mann-Whitney test; $n$, number of metaphase cells, two independent experiments (Kruskal-Wallis: Control $P=0.7215 \mathrm{~ns}, \mathrm{HA} \beta 1 P=0.92 \mathrm{~ns}$ ). Scale bar, $5 \mu \mathrm{m}(\mathbf{a}, \mathbf{e}), 10 \mu \mathrm{m}(\mathbf{d}, \mathbf{f}-\mathbf{h})$. 
previous data showing that ligand-independent activation of integrin $\beta 1$ elicits Cas phosphorylation ${ }^{23}$ and its direct interaction with $\mathrm{FAK}^{48,49}$, we also examined the localization of phosphorylated Cas. As shown, P-Cas also becomes localized at the mitotic cortex and the same is true for Src, the principle kinase shown to phosphorylate Cas (Fig. 7a) (refs 50,51). In addition, the active forms of all three proteins display lateral cortical polarity in a similar manner to active $\beta 1$ (Fig. $7 \mathrm{a}$, white arrowheads). Importantly, loss of $\beta 1$ cortical activation through $\mathrm{P} 4 \mathrm{C} 10$ treatment led to a reduction of $\mathrm{P}$-Cas and P-Src cortical localization suggesting that the localization/phosphorylation of these proteins on the cortex of mitotic cells depends on $\beta 1$ activation (Fig. 7b). These results suggest that a cortical mechanosensory complex (CMC) forms at the lateral regions of

a

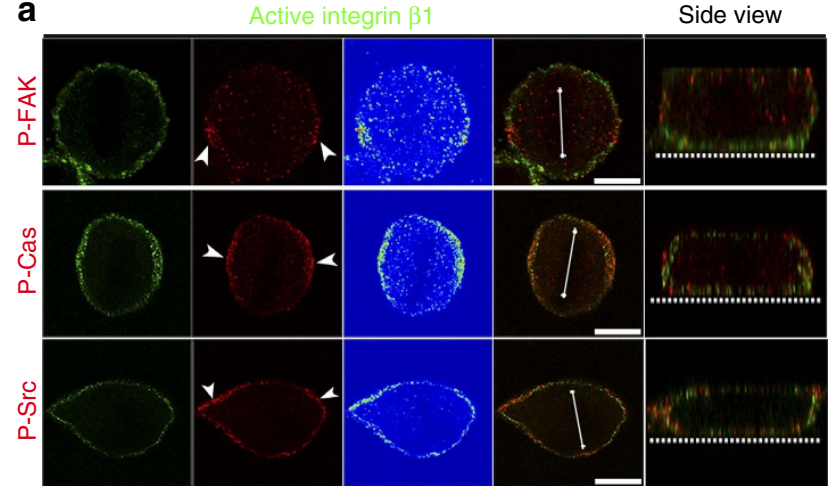

b

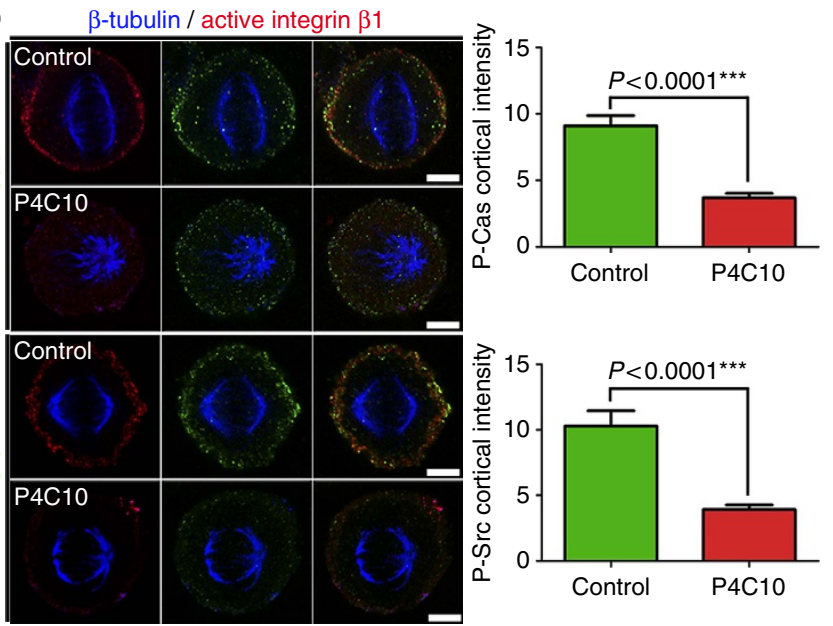

Figure 7 | An integrin $\beta 1$-based cortical mechanosensory complex is formed at the lateral cortex of mitotic cells. (a) Optical sections, colour intensity-coded images and side views of representative metaphase HeLa cells co-stained for active $\beta 1$ and phosphorylated active forms of FAK, Cas or Src. The white arrowheads indicate the polarized cortical crescent of the phosphorylated forms of the above proteins. The white line represents the metaphase plate and the dashed line shows the basal surface. (b) Optical sections at the spindle plane of metaphase control HeLa cells or cells treated with the P4C10 antibody. All cells were imaged under the same conditions. Cells were co-stained for $\beta$-tubulin, active $\beta 1$ (9EG7) and phosphorylated Cas or Src. The plots show the average cortical intensity of $\mathrm{P}$-Cas and P-Src in control and P4C10-treated cells. mean \pm s.e.m.: P-Cas control 9.106 $\pm 0.7618, n=33$; P-Cas P4C10 $3.691 \pm 0.3323, n=34$; P-Src control $10.30 \pm 1.155, n=35$; P-Src P4C10 3.916 $\pm 0.3537, n=30$. Analysed by Mann-Whitney test; $n$, number of metaphase cells, two independent experiments (Kruskal-Wallis: for P-Cas Control $P=0.0715 \mathrm{~ns}, \mathrm{P} 4 \mathrm{C} 10$ $P=0.2177 \mathrm{~ns}$; for P-Src Control $P=0.0657 \mathrm{~ns}, \mathrm{P} 4 \mathrm{C} 10 \mathrm{P}=0.2510 \mathrm{~ns}$ ). Scale bar, $10 \mu \mathrm{m}$ (a), $5 \mu \mathrm{m}$ (b). the cortex in non-polar adherent cells and asked if this complex also forms in polarized cells. Staining of MDCK monolayers revealed that active $\beta 1, \mathrm{P}-\mathrm{FAK}, \mathrm{P}-\mathrm{Cas}$ and $\mathrm{P}-\mathrm{Src}$ are localized at the lateral aspect of the cortex specifically in mitotic cells in a similar manner to HeLa cells (Supplementary Fig. 7a,b). Furthermore, examining the localization of P-FAK, P-Cas and P-Src in the outermost epithelium of Xenopus embryos reveals that although all cells of the epithelium display staining on the lateral regions of the cortex (especially multiciliated cells), mitotic epithelial cells display a clear elevation of this signal (Supplementary Fig. 7c, white arrowheads). Overall, the above data suggest that ligand-independent $\beta 1$ activation leads to the formation of conserved cortical complex in mitotic cells irrespective of cell or tissue context.

The members of the CMC cooperate to orient the spindle. Our data suggest that a complex composed of FAK, Cas and Src forms on active $\beta 1$ at the lateral cortex of mitotic cells and regulates spindle responses to external forces. We went on to explore the interactions between its members that are important in this process. Expression of a Cas-binding defective mutant of FAK (FAK P712/715A $)^{48}$ failed to rescue spindle orientation defects in both FAK null mouse embryonic fibroblasts derived from FAK $\mathrm{KO}$ mice ${ }^{52}$ and in epithelial cells of FAK morphant Xenopus embryos, suggesting that the FAK-Cas interaction is important (Fig. 8a,b, Supplementary Fig. 8a). Since Cas had not been previously implicated in this process we examined Cas null fibroblasts derived from Cas knockout mice ${ }^{53}$ that, as shown, display spindle misorientation unlike Cas reconstituted cells (Fig. 8c,d). In addition, expression of the Cas $\Delta \mathrm{SH} 3$ mutant, which does not bind FAK, fails to rescue defects of Cas null cells confirming the importance of this interaction in spindle orientation $^{48}$ (Fig. 8c,d). Given the previously characterized role of the substrate domain (SD) of Cas in mechanotransduction from FAs ${ }^{54}$, we asked if phosphorylation of Cas is important. As shown, expression of the Cas $15 \mathrm{~F}$ mutant failed to rescue spindle misorientation (Fig. 8c,d). The SD domain of Cas is a wellcharacterized substrate of Src kinases ${ }^{50,51}$ and it has been previously shown that the Src kinase activity is indispensable for force-dependent spindle orientation ${ }^{31}$. This raised the possibility that during mitosis Cas is phosphorylated by Src. SD phosphorylation is mediated through two distinct mechanisms; either through direct binding of the $\mathrm{SH} 3$ domain of $\mathrm{Src}$ to the C-terminal polyproline region of Cas or via indirect association of Src with Cas through FAK ${ }^{55}$. As shown, expression of the Cas mPR mutant in which the Src-Cas interaction is impaired rescues as effectively as WT Cas ${ }^{56-58}$ (Fig. 8c,d), suggesting that direct binding of Src on Cas is dispensable. Expression of a Src binding mutant of FAK (Y397F) in FAK nulls, however, was significantly less effective in rescuing spindle orientation defects compared with WT FAK, suggesting that Src binding on FAK is important (Fig. 8a,b). The requirement of Y397 and of Src's kinase activity to phosphorylate Cas in the orientation of the mitotic spindle were confirmed in vivo, where use of a Src inhibitor also blocked Cas phosphorylation, providing further support for the notion that the $\beta 1$-dependent $\mathrm{CMC}$ is conserved in the embryo (Supplementary Fig. 8b,c). Overall, these data show that direct interaction of FAK with Cas and Src is critical for correct spindle orientation and suggest that during mitosis a complex forms downstream of force-dependent integrin $\beta 1$ activation in which FAK acts as a scaffold to elicit Src-dependent Cas phosphorylation.

\section{Discussion}

The involvement of integrins in spindle orientation has been established for almost a decade now. Integrin $\beta 1$ knockout mice 
a

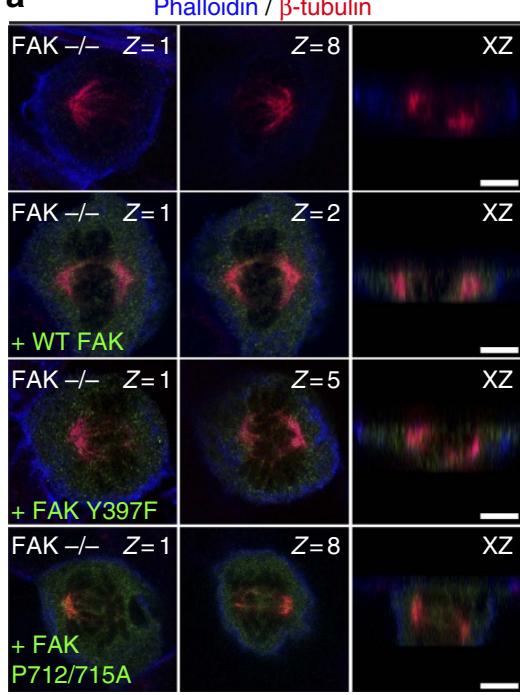

b

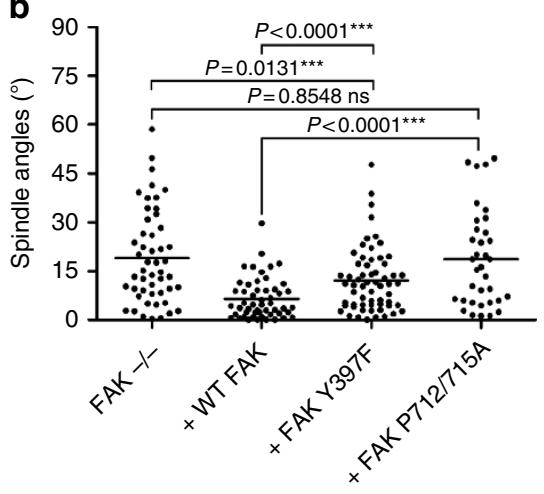

C Phalloidin / $\beta$-tubulin

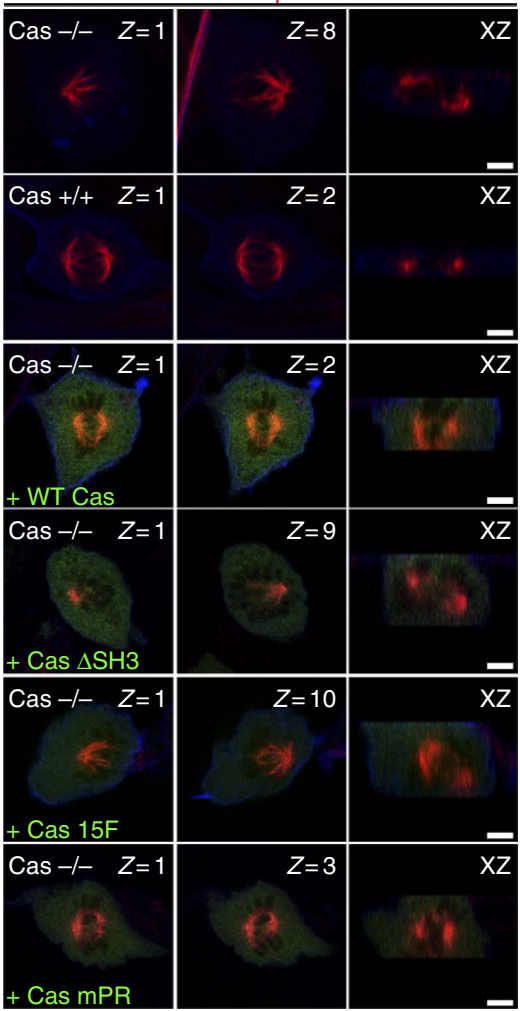

d

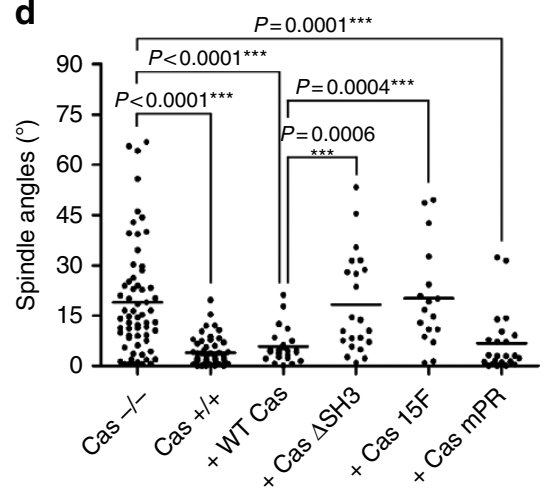

Figure 8 | Interactions between the members of the CMC guide mitotic spindle orientation. (a) Optical sections at the plane of each spindle pole and side views of FAK nulls, or FAK nulls transfected with the indicated constructs (signal shown in green) stained for $\beta$-tubulin and actin. (b) Scatter plot of the substrate to spindle angles of metaphases cells described in a. Mean \pm s.e.m.: FAK $-/-19.04 \pm 2.028^{\circ}, n=50 ;$ FAK $-/-+$ WT FAK $6.507 \pm 0.8685^{\circ}$, $n=52 ;$ FAK $-/$ - FAK Y397F $12.14 \pm 1.263^{\circ}, n=61$; FAK - / - +FAK P712/715 A 18.63 $\pm 2.501^{\circ}, n=35 ; P$ values calculated by Mann-Whitney test; $n$, number of metaphase cells, two independent experiments (Kruskal-Wallis: FAK $-/-P=0.5405 \mathrm{~ns},+$ WT FAK $P=0.2432 \mathrm{~ns}$, +FAK Y397F

$P=0.1732 \mathrm{~ns},+$ FAK P712/715 A $P=0.0 .8886 \mathrm{~ns}$ ). (c) Optical sections at the plane of each spindle pole and side views of Cas nulls, Cas reconstituted cells or Cas nulls transfected with the indicated constructs (shown in green) stained for $\beta$-tubulin and actin. (d) Scatter plot of the substrate to spindle angles of metaphases cells described in c. Mean \pm s.e.m.: Cas $-/-18.97 \pm 2.102^{\circ}, n=63$; Cas $+/+3.825 \pm 0.5526^{\circ}, n=57 ;$ Cas $-/-+$ WT Cas $5.805 \pm 1.062^{\circ}, n=24 ;$ Cas $-/-+$ Cas $\Delta$ SH3 18.24 $\pm 3.173^{\circ}, n=22 ;$ Cas $-/-+$ Cas 15 F 20.09 $\pm 3.660^{\circ}, n=17 ;$ Cas $-/-+$ Cas mPR 6.703 $\pm 1.882^{\circ}$, $n=23$; $P$ values calculated by Mann-Whitney test; $n$, number of metaphase cells, two independent experiments (Kruskal-Wallis: Cas $-/-P=0.6765$ ns, Cas $+/+P=0.1978 \mathrm{~ns},+$ WT Cas $P=3967 \mathrm{~ns},+$ Cas $\Delta \mathrm{SH} 3 P=0.7745 \mathrm{~ns},+$ Cas $15 \mathrm{~F} P=0.2913 \mathrm{~ns},+$ Cas mPR $P=0.1564 \mathrm{~ns})$. Scale bar, $5 \mu \mathrm{m}(\mathbf{a}, \mathbf{c})$.

display orientation defects in asymmetric divisions of basal keratinocytes during stratification ${ }^{13}$, while disruption of $\beta 1$-dependent cell adhesion leads to spindle misorientation with respect to the substrate ${ }^{12}$. Studies have implicated integrins in the regulation of divisions in polarized epithelial cells ${ }^{15,17}$. However, a direct role in spindle orientation in this context is difficult to conclude given the fact that integrins regulate basement membrane deposition and apicobasal polarity, raising the possibility that the observed spindle orientation defects may be secondary to defects in epithelial polarity ${ }^{16}$. Overall, intergins are broadly implicated in the regulation of spindle orientation through their interactions with ECM components and signalling from adhesion complexes suggesting that their role in spindle orientation stems from their role in cell adhesion.

In this study, we show that integrin $\beta 1$ is involved in spindle orientation independently from its role in cell adhesion and provide insight into the molecular link between spindle orientation and integrins. We show that integrin $\beta 1$ becomes activated 
on the mitotic cortex in a polarized manner, displaying asymmetry along the apicobasal axis ( $z$ axis) and at the plane of the spindle ( $x-y$ plane). Specifically, active $\beta 1$ is enriched at the lateral regions of the cortex where the RFs terminate, while there is no active $\beta 1$ at the apical regions that are devoid of RFs. The distribution of active $\beta 1$ at the plane of the spindle is polar correlating with the distribution of RFs and displaying enrichment at the spindle capture sites. We have previously shown that spindle orientation in non-polarized cells along the $z$-axis and the $x y$ plane both rely on the three-dimensional distribution of RFs and subsequently the distribution of forces on the cortex ${ }^{5}$. Similarly, the asymmetric activation of integrin $\beta 1$ in areas that are not in contact with ECM depends on the asymmetry in the distribution of the RFs, suggesting that force transmitted through the RFs activates $\beta 1$ on the cortex.

The notion that integrin $\beta 1$ can be activated in a ligandindependent manner was initially proposed by Ferraris et al. Through a series of experiments, taking advantage of UPAR's ability to bind $\mathrm{VN}$, the authors showed that integrin $\beta 1$ can be activated through membrane tension in cells adhering in an integrin-independent manner. In addition, the authors showed that this activation leads to signalling from active $\beta 1$ (ref. 23). The physiological relevance of this mode of activation and whether it actually occurs in parallel with ligand-dependent activation was not clear, given the artificial nature of the system used. Nevertheless, the authors convincingly demonstrated that integrin $\beta 1$ can be activated by membrane tension and here we provide evidence that $\beta 1$ can be activated through direct application of force and that ligand-dependent and -independent activation of integrin $\beta 1$ co-exist in mitotic cells. Specifically, we show that cells adhering in an integrin $\beta 1$-independent manner display integrin $\beta 1$ activation at the lateral mitotic cortex that is independent from $\beta 1$ activation at the cell-ECM interface. It should be noted that although it was previously suggested that some integrin heterodimers that include the $\beta 1$ subunit can bind $\mathrm{E}$-cadherin or $\mathrm{VN}^{59,60}$, under the conditions of these experiments no $\beta 1$ activation could be detected at the cell-substrate interface.

The activation of integrin $\beta 1$ on the cortex of mitotic cells in conjunction with previous work implicating it in spindle orientation, suggests that $\beta 1$ has ligand-dependent and ligandindependent roles in this process. Ligand-dependent roles stem from the involvement of integrins as receptors for cell adhesion and additionally, through the requirement of signalling through $\beta 1$ for proper polarization of epithelia ${ }^{16}$. Separating the two is not trivial however, our data showing that loss of active $\beta 1$ from the cortex as well as loss of its asymmetric distribution lead to spindle misorientation, suggest that cortical activation of $\beta 1$ is a major determinant for correct spindle orientation. Importantly, inhibition of $\beta 1$ activation in cells that orient in an ECM-independent fashion also leads to spindle misorientation, providing strong support for a ligand-independent role of $\beta 1$ in this process.

How is $\beta 1$ activation linked to force sensing by the spindle? Our data show that proteins which normally reside at FAs are recruited to the lateral regions of the cell cortex during mitosis where they co-localize with and display similar asymmetric distributions as active $\beta 1$. The recruitment of these proteins to the cortex depends on integrin $\beta 1$, suggesting that $\beta 1$ activation leads to the formation of a conserved cortical complex responsible for facilitating signal transduction from force activated $\beta 1$ to the spindle. Disrupting the interactions between its members, results in defective spindle orientation in both adherent cells and embryonic epithelia.

We propose that in mitotic cells there are two pools of active $\beta 1$ one at the cell-ECM interface which is ligand and force

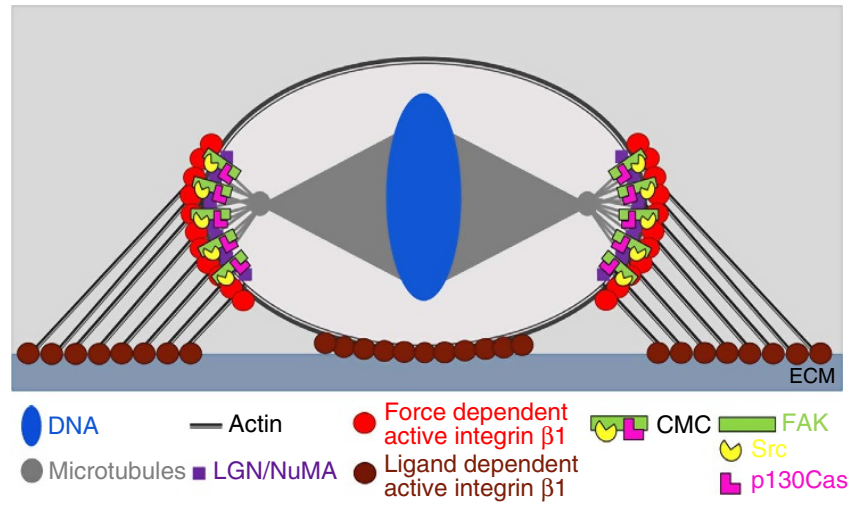

Figure 9 | Ligand-independent integrin $\beta 1$ activation guides spindle orientation. Schematic illustration of the distribution of the two pools of active integrin $\beta 1$ in mitotic cells: Ligand-dependent active $\beta 1$ is localized at the cell-ECM interphase whereas the ligand-independent and force-dependent active $\beta 1$ is enriched at the areas where the RFs terminate on the lateral cortex and specifically enriched at the spindle capture sites. Integrin $\beta 1$ activation on the lateral cortex results in the establishment of the $C M C$, which guides spindle capture in response to force.

dependent and one at the mid-lateral regions of the cortex, which is force dependent but ligand independent (Fig. 9). Although the ligand-dependent pool is essential for cell adhesion it is not directly involved in spindle orientation. In contrast, the ligandindependent pool is necessary for correct spindle responses to external force through the establishment of the CMC (Fig. 9). The mechanism through which the CMC influences spindle capture is not clear however, a subcortical actin pool has been suggested to interact with myosin 10 at the astral $\mathrm{MTs}^{61}$ and to influence their capture sites on the cortex ${ }^{4}$. Phosphorylation of Cas initiates Rac activation $^{62,63}$ and it is possible that this actin pool is regulated through localized activation of Rac. In agreement with this, Rac activity is polarized and regulates anchoring of the spindle in mammalian oocytes ${ }^{64}$. The possibility that cortical $\beta 1$ activation guides astral MTs is supported by studies showing that MTs target sites of integrin activation and the presence of active integrins stabilizes MTs at the cell cortex ${ }^{46,65}$. Since cortical activation of $\beta 1$ depends on RF-derived forces and the greatest forces are exerted at the mid-lateral region where the RFs are longer, astral MTs would presumably be stabilized preferentially at these areas, promoting capture at the lateral rather than the basal cortex explaining why the spindle is oriented parallel to the substrate. In addition, the exclusion of a vertical division can also be explained by the absence of the capture machinery at the apical cortex of the cells where no force is applied. However, since our data suggest that $\beta 1$ activation does not directly influence the recruitment of LGN/NuMA to the cortex, it is likely that the exclusion of LGN/NuMA from the apicobasal cortex in metaphase cells is secondary to lateral capture and a result of the chromosome-derived RanGTP gradient shown to restrict the localization of NuMA-LGN ${ }^{66}$.

Overall, our work reveals a conserved ligand-independent role of integrin $\beta 1$ in spindle orientation and suggests that a CMC composed of well-characterized FA proteins is responsible for spindle responses to external force.

\section{Methods}

Cell culture and transfections. HeLa and MDCK cells (ATCC) were cultured in DMEM with 10\% FBS. FAK null cells (ATCC) were cultured in DMEM with $10 \%$ FBS and $1 \mathrm{mM}$ sodium pyruvate. Cas null and Cas reconstituted cells (provided by Dr Sara Cabodi) were cultured in DMEM with $10 \%$ FBS and $1 \mathrm{mML}-$ Glutamine. MCF10A cells (ATCC) were cultured in DMEM-F12 supplemented with $5 \%$ horse serum, $20 \mathrm{ng} \mathrm{ml}^{-1} \mathrm{EGF}, 0.5 \mathrm{mg} \mathrm{ml}^{-1}$ hydrocortisone, $100 \mathrm{ng} \mathrm{ml}^{-1}$ Cholera Toxin 
and $10 \mu \mathrm{g} \mathrm{ml}^{-1}$ Insulin. Transfections in all cell lines were performed with Lipofectamin 2,000 (11668019, Invitrogen) according to the manufacturer's instructions.

Cell adhesion on substrates. Coating of charged coverslips with FN and VN was performed for $2 \mathrm{~h}$ at $37^{\circ} \mathrm{C}$ prior cell seeding. PLL coating was performed for $30 \mathrm{~min}$ at room temperature (RT). In all experiments except those where parallel cell adhesion on FN, VN or PLL was performed, cells were adhered overnight on $10 \mu \mathrm{g} \mathrm{ml}^{-1} \mathrm{FN}$ (Invitrogen) coated coverslips. For experiments comparing cells seeded on FN versus VN, cells were seeded on $10 \mu \mathrm{g} \mathrm{ml}^{-1} \mathrm{FN}$ or $20 \mu \mathrm{g} \mathrm{ml}^{-1} \mathrm{VN}$ (Sigma) for $4 \mathrm{~h}$ before fixation to preclude $\mathrm{FN}$ deposition and fibrillogenesis on VN, which was verified via FN immunostaining. Cells on PLL were adhered for $1 \mathrm{~h}$ before fixation. MCF10A cells were seeded on silanized coverslips coated with mouse E-cadherin-Fc chimera (748-EC-050, R\&D Systems). Silanization of charged coverslips was performed according to established protocols ${ }^{39}$. Briefly, coverslips were hydroxylated in saturated $\mathrm{KOH}$ in isopropanol, overnight at RT, washed three times with water and dried. Then coverslips were treated with $1 \%$ (3-aminopropyl)trimethoxysilane (281778, Sigma) in toluene, overnight at RT, washed three times in toluene and dried. E-cadherin coating was performed at $3 \mu \mathrm{g} \mathrm{ml}{ }^{-1}$ for $2 \mathrm{~h}$ at $37^{\circ} \mathrm{C}$ and crosslinked. MCF10A cells were mechanically detached in PBS containing $10 \mathrm{mM}$ EDTA and 2\% BSA and seeded in DMEM-F12 media for 90 min before fixation. Plating of cells on FN micropatterned coverslips (CYTOO) was performed according to the manufacturer's protocol.

Magnetic beads. A mixture of $1.5 \mu \mathrm{g}$ of E-cadherin-Fc and $2 \mathrm{mg} \mathrm{ml}^{-1}$ of Protein A dynabeads (100.02D, Invitrogen) was incubated for $20 \mathrm{~min}$ at RT with intermediate slight vortex steps. Beads were recovered with the use of a magnet, washed twice in PBS, resuspended in $30 \mu \mathrm{l}$ of DMEM-F12 and added for $2 \mathrm{~h}$ in the absence of serum on MCF10A seeded cells on coverslips. Cells were then either fixed directly or after the beads were pulled for $15 \mathrm{~min}$ by placing a magnet at the edge of the coverslip. For addressing the effects of application of external force on spindle orientation, cells with attached beads were either fixed directly or after the beads were pulled for $30 \mathrm{~min}$ by placing the magnet above them.

DNA Constructs and morpholinos. All plasmids generated were verified by sequencing.

All FAK mutants were generated from the FAK chicken variant (GenBank AAA48765.1). The constructs WT FAK, FAK K454R and FAK Y397F in pCS2 ++ vector have been described (citations). The hemaglutinin (HA) or GFP-tagged version of the FAK P712/715A construct was generated by site-directed mutagenesis using the set of primers F/FAK P712/715A: 5'-GGATCA GATGAAGCTGCTCCCAAGGCCAGCAGGCCTGGTTAC- $3^{\prime}$ and R/FAK P712/715A: 5'-GTAACCAGGCCTGCTGGCCTTGGGAGCAGCTTCATCTGA TCC- $3^{\prime}$. The plasmid histone GFP pCS2 + was kindly provided by Chenbei Chang lab. The pEGFP C1-LGN construct was kindly provided by Fumiko Toyoshima Lab. The HA $\beta 1$ pSP64T construct was provided by Douglas DeSimone lab. The pCS2 GFP-Utrophin plasmid was provided by Dr John Wallingford. All p130Cas constructs were provided by Dr Steven Hanks. The sequence of FAK morpholino (MO) is $5^{\prime}$-TTGGGTCCAGGTAAGCCGCAGCCAT- ${ }^{\prime}$.

Immunostaining. Immunofluorescence on HeLa, MDCKs, FAK null and Cas null cells was carried out as follows: cells were fixed for $15 \mathrm{~min}$ in $4 \%$ paraformaldehyde. When staining phosphorylated proteins, fixation was performed in the presence of $1 \mathrm{mM}$ Sodium Orthovanadate. Fixation was followed by addition of $50 \mathrm{mM}$ glycine. When active or total integrin $\beta 1$ staining was performed, cells were first blocked in $10 \%$ normal donkey serum (Jackson Immunoresearch) and incubated with the integrin antibodies before triton treatment to preserve the specificity of the antibodies against their epitopes for $90 \mathrm{~min}$ at RT. Cells were then washed, permeabilized using $0.03 \%$ Triton-X for $6 \mathrm{~min}$, blocked again for $15 \mathrm{~min}$ and incubated with the primary antibodies for $90 \mathrm{~min}$ RT. The primary antibodies used are: active integrin $\beta 1$ 9EG7 (1:250, 550531 BD Pharmigen), active integrin $\beta 1$ HUTS-21 (1:250, 556048, BD Pharmigen), integrin $\beta 1$ K20 (1:50, sc-18887, Santa Cruz), integrin $\beta 1$ TS2/16 (1:500, sc-53711, Santa Cruz), integrin $\beta 1$ AIIB2 (1:500, Hybridoma Bank), $\beta$-tubulin (1:200, E7, Hybridoma Bank), FAK (1:500, 05-537, Millipore), Paxillin (1:1,000, 610569, BD Biosciences), P-Ser10 H3 (1:1,000, 06-570, Millipore), P-Y576 FAK (1:200, 700013, Invitrogen), P-Y165 CAS (1:50, 4015, Cell Signaling), P-Y416 Src (1:100, 2101, Cell Signaling), $\beta$-catenin (1:500, sc-7199, Santa Cruz), NuMA (1:500, ab36999, Abcam). Cells were then washed several times in PBS and incubated with secondary antibodies. Staining of the $\mathrm{f}$-actin was performed using phalloidin (Invitrogen), whereas DNA staining was performed by the use of TO-PRO 3 (Invitrogen). Mounting was performed in prolong gold antifade media.

Embryos were fixed in 10\% 10XMEMFA, 10\% 3.7\% formaldehyde and $80 \%$ water for $2 \mathrm{~h}$ at RT, permeabilized in PBST $(1 \times$ PBS, $0.5 \%$ Triton, $1 \%$ dimethyl sulfoxide) and blocked for $30 \mathrm{~min}$ in 10\% Normal Donkey serum. Primary antibodies were incubated overnight at $4{ }^{\circ} \mathrm{C}$. The primary antibodies used are: $\beta$-tubulin (1:200, E7, Hybridoma Bank), GFP (1:500, A11122, Invitrogen), HA (1:250, sc-805, Santa Cruz), $\beta$-catenin (1:500, sc-7199, Santa Cruz), FN (1:200, $4 \mathrm{H} 2$, provided Dr Douglas DeSimone), integrin $\beta 1$ (1:50, 8C8, Hybridoma Bank).
Embryos were washed in PBST and incubated for $2 \mathrm{~h}$ with secondary antibodies at $\mathrm{RT}$, washed several times and post-fixed in 1XMEMFA. Clearing of the embryos was performed after methanol dehydration followed by immersing them in Murray's Clearing Medium.

Live cell staining. Live imagining of active integrin $\beta 1$ was performed by treating seeded cells for $30 \mathrm{~min}$ with the $9 \mathrm{EG} 7$ antibody $\left(0.15 \mu \mathrm{g} \mathrm{ml}^{-1}\right)$ in media, followed by three media washes and incubation with Cy-3 anti-rat secondary antibody for $30 \mathrm{~min}$. Cells were then washed with media and imaged.

Drugs, peptides and antibodies treatments. HeLa cells were treated with $10 \mathrm{nM}$ of NZ for $30 \mathrm{~min}$ and $0.5 \mu \mathrm{g} \mathrm{ml}^{-1}$ of Cyto D for $1 \mathrm{~h}$ at $37^{\circ} \mathrm{C}$. For integrin blocking experiments, the $\mathrm{P} 4 \mathrm{C} 10$ antibody (antibody supernatant from Hybridoma Bank, 1:100 dilution) was added to the cells for $30 \mathrm{~min}$ at $37^{\circ} \mathrm{C}$ before fixation. For integrin overactivation experiments, cells were treated with $10 \mu \mathrm{g} \mathrm{ml}^{-1}$ or $50 \mu \mathrm{g} \mathrm{ml}^{-1}$ of RGD peptide for $1 \mathrm{~h}$, or with $0.625 \mu \mathrm{g} \mathrm{ml}^{-1}$ 9EG7 antibody for $1 \mathrm{~h}$ or with $10 \mu \mathrm{g} \mathrm{ml}^{-1}$ of RGD for 30 min followed by treatment with $10 \mu \mathrm{g} \mathrm{ml}^{-1}$ of RGD and $0.625 \mu \mathrm{g} \mathrm{ml}^{-1}$ 9EG7 for another $30 \mathrm{~min}$ at $37^{\circ} \mathrm{C}$. Xenopus embryos were treated with $8 \mu \mathrm{M}$ of Src inhibitor PP2 (Sigma) from stage 9 until they were fixed at stage 15 .

Embryos and manipulations. Xenopus laevis embryos were staged according to Nieuwkoop and Faber (1967). Embryos were fertilized in vitro and dejellied using $1.8 \%$ L-cysteine, $\mathrm{pH} 7.8$, then maintained in $0.1 \times$ Marc's Modified Ringer's. Microinjections were performed in $4 \%$ Ficoll in $0.3 \times$ Marc's Modified Ringer's. For spindle orientation in the Xenopus outermost epidermis embryos were injected with $50 \mathrm{ng}$ of FAK MO at the one cell stage. All FAK constructs were co-injected with the FAK MO at $300 \mathrm{pg}$. Embryos were allowed to develop until stage 9, where animal caps were dissected and cultured in Danilchik's for Amy (DFA; $53 \mathrm{mM} \mathrm{NaCl}_{2}, 5 \mathrm{mM}$ $\mathrm{Na}_{2} \mathrm{CO}_{3}, 4.5 \mathrm{mM}$ potassium gluconate, $32 \mathrm{mM}$ sodium gluconate, $1 \mathrm{mM} \mathrm{CaCl}_{2}$, $1 \mathrm{mM} \mathrm{MgSO}_{4}$ ) until stage 15, when they were fixed and processed for immunofluorescence. HA 1 construct was injected at the one cell stage at $300 \mathrm{pg}$.

Imaging. Cells and embryos were imaged on a laser scanning confocal microscope (LSM710 Zeiss).

Statistical Analysis. For all independent experiments, at least two replicates were performed for each experiment (defining as replicate each coverslip with attached cells). The data obtained from the replicates were pulled together and analysed either with $t$-test for parametric distributions or with Mann-Whitney test for non-parametric distributions as judged by the D'Agostino-Pearson normality test. When noted in the figure legends, data were also analysed with one-way analysis of variance or Kruskal-Wallis tests to estimate the variation within each experimental group between the replicates.

Quantification of the orientation of the division axis of metaphase cultured and epithelial cells was carried out with ImageJ using the Z-projections of the images. The angle between the line connecting the two spindle poles and the line extending from the one spindle pole parallel to the substrate was measured. Quantification of spindle orientation in the cells of the outermost cell layer of the Xenopus epithelium was carried out as described above, by measuring the angle between the line connecting the two spindle poles and the line extending from the one spindle pole parallel to the apical surface of the cell. Statistical analysis of spindle orientation including two-tailed unpaired $t$-test for parametric distributions and graph construction were performed by the GraphPad software.

Intensities and cell-matrix contact areas were measured using the Zen 2010 software. Intensity ratios were calculated in Microsoft Excel 2013 and all measurements were analysed with GraphPad.

The correlation of spindle orientation to the active integrin $\beta 1$ cortical polarity crescent was performed by measuring the angle formed between the line connecting the centre of the metaphase plate perpendicularly to the cell cortex and the line extending from the centre of the active integrin $\beta 1$ cortical crescent towards the centre of the metaphase plate. The angular distribution plot was constructed by using MATLAB.

The correlation of spindle misorientation with the levels of integrin $\beta 1$ cortical activation was performed by measuring the spindle angle and the ratio of basal to mid-lateral cortex intensity of active integrin $\beta 1$ for each metaphase cell. Pearson correlation coefficient $(r)$ was calculated for the two variances, where $-1<r<1$ and graphs were constructed in Microsoft Excel 2013.

The correlation of LGN cortical crescent with spindle orientation was performed by measuring the angle $\alpha$ (Supplementary Fig. 6a) formed between the line connecting the centre of the metaphase plate perpendicularly to the cell cortex and the line extending from the centre of LGN cortical crescent towards the centre of the metaphase plate. The correlation of NuMA cortical centre with spindle orientation was performed by measuring the angle $\beta$ (Supplementary Fig. 6d) formed between the extending line connecting the two spindle poles towards the cell cortex and the line extending from the centre of NuMA cortical crescent towards the proximal spindle pole. 


\section{References}

1. Morin, X. \& Bellaiche, Y. Mitotic spindle orientation in asymmetric and symmetric cell divisions during animal development. Dev. Cell 21, 102-119 (2011).

2. Pease, J. C. \& Tirnauer, J. S. Mitotic spindle misorientation in cancer--out of alignment and into the fire. J. Cell Sci. 124, 1007-1016 (2011).

3. McNally, F. J. Mechanisms of spindle positioning. J. Cell Biol. 200, 131-140 (2013)

4. Fink, J. et al. External forces control mitotic spindle positioning. Nat. Cell Biol. 13, 771-778 (2011).

5. Petridou, N. I. \& Skourides, P. A. FAK transduces extracellular forces that orient the mitotic spindle and control tissue morphogenesis. Nat. Commun. 5, 5240 (2014)

6. Campinho, P. et al. Tension-oriented cell divisions limit anisotropic tissue tension in epithelial spreading during zebrafish epiboly. Nat. Cell Biol. 15, 1405-1414 (2013)

7. Mitra, S. K., Hanson, D. A. \& Schlaepfer, D. D. Focal adhesion kinase: in command and control of cell motility. Nat. Rev. Mol. Cell Biol. 6, 56-68 (2005).

8. Goldmann, W. H. Mechanotransduction and focal adhesions. Cell Biol. Int. 36, 649-652 (2012)

9. Zebda, N., Dubrovskyi, O. \& Birukov, K. G. Focal adhesion kinase regulation of mechanotransduction and its impact on endothelial cell functions. Microvasc. Res. 83, 71-81 (2012)

10. Campbell, I. D. \& Humphries, M. J. Integrin structure, activation, and interactions. Cold Spring Harb. Perspect. Biol. 3, a004994 (2011).

11. Toyoshima, F., Matsumura, S., Morimoto, H., Mitsushima, M. \& Nishida, E. PtdIns(3,4,5)P3 regulates spindle orientation in adherent cells. Dev. Cell 13, 796-811 (2007)

12. Toyoshima, F. \& Nishida, E. Integrin-mediated adhesion orients the spindle parallel to the substratum in an EB1- and myosin X-dependent manner. EMBO J. 26, 1487-1498 (2007).

13. Lechler, T. \& Fuchs, E. Asymmetric cell divisions promote stratification and differentiation of mammalian skin. Nature 437, 275-280 (2005).

14. Fernandez-Minan, A., Martin-Bermudo, M. D. \& Gonzalez-Reyes, A. Integrin signaling regulates spindle orientation in Drosophila to preserve the follicular-epithelium monolayer. Curr. Biol. 17, 683-688 (2007).

15. Chen, J. \& Krasnow, M. A. Integrin Beta 1 suppresses multilayering of a simple epithelium. PLoS ONE 7, e52886 (2012).

16. Ojakian, G. K. \& Schwimmer, R. Regulation of epithelial cell surface polarity reversal by beta 1 integrins. J. Cell Sci. 107(Pt 3): 561-576 (1994).

17. Akhtar, N. \& Streuli, C. H. An integrin-ILK-microtubule network orients cell polarity and lumen formation in glandular epithelium. Nat. Cell Biol. 15, 17-27 (2013).

18. Morris, E. J., Assi, K., Salh, B. \& Dedhar, S. Integrin-linked kinase links dynactin-1/dynactin-2 with cortical integrin receptors to orient the mitotic spindle relative to the substratum. Sci. Rep. 5, 8389 (2015).

19. Petridou, N. I., Stylianou, P. \& Skourides, P. A. A dominant-negative provides new insights into FAK regulation and function in early embryonic morphogenesis. Development 140, 4266-4276 (2013).

20. Marsden, M. \& DeSimone, D. W. Regulation of cell polarity, radial intercalation and epiboly in Xenopus: novel roles for integrin and fibronectin. Development 128, 3635-3647 (2001).

21. Mitchison, T. J. Actin based motility on retraction fibers in mitotic PtK2 cells. Cell Motil. Cytoskeleton 22, 135-151 (1992).

22. Friedland, J. C., Lee, M. H. \& Boettiger, D. Mechanically activated integrin switch controls alpha5betal function. Science 323, 642-644 (2009).

23. Ferraris, G. M. et al. The interaction between uPAR and vitronectin triggers ligand-independent adhesion signalling by integrins. EMBO J. 33, 2458-2472 (2014).

24. Byron, A. et al. Anti-integrin monoclonal antibodies. J. Cell Sci. 122, 4009-4011 (2009).

25. Luque, A. et al. Activated conformations of very late activation integrins detected by a group of antibodies (HUTS) specific for a novel regulatory region (355-425) of the common beta 1 chain. J. Biol. Chem. 271, 11067-11075 (1996).

26. Takada, Y. \& Puzon, W. Identification of a regulatory region of integrin beta 1 subunit using activating and inhibiting antibodies. J. Biol. Chem. 268, 17597-17601 (1993)

27. Tsuchida, J., Ueki, S., Saito, Y. \& Takagi, J. Classification of 'activation' antibodies against integrin betal chain. FEBS Lett. 416, 212-216 (1997).

28. Bazzoni, G., Shih, D. T., Buck, C. A. \& Hemler, M. E. Monoclonal antibody 9EG7 defines a novel beta 1 integrin epitope induced by soluble ligand and manganese, but inhibited by calcium. J. Biol. Chem. 270, 25570-25577 (1995).

29. Lenter, M. et al. A monoclonal antibody against an activation epitope on mouse integrin chain beta 1 blocks adhesion of lymphocytes to the endothelial integrin alpha 6 beta 1. Proc. Natl. Acad. Sci. USA 90, 9051-9055 (1993).

30. Thery, M., Jimenez-Dalmaroni, A., Racine, V., Bornens, M. \& Julicher, F. Experimental and theoretical study of mitotic spindle orientation. Nature 447, 493-496 (2007)
31. Thery, M. et al. The extracellular matrix guides the orientation of the cell division axis. Nat. Cell Biol. 7, 947-953 (2005).

32. Jordan, M. A., Thrower, D. \& Wilson, L. Effects of vinblastine, podophyllotoxin and nocodazole on mitotic spindles. Implications for the role of microtubule dynamics in mitosis. J. Cell Sci. 102(Pt 3): 401-416 (1992).

33. Bershadsky, A., Chausovsky, A., Becker, E., Lyubimova, A. \& Geiger, B. Involvement of microtubules in the control of adhesion-dependent signal transduction. Curr. Biol. 6, 1279-1289 (1996).

34. Mould, A. P., Akiyama, S. K. \& Humphries, M. J. The inhibitory anti-betal integrin monoclonal antibody 13 recognizes an epitope that is attenuated by ligand occupancy. Evidence for allosteric inhibition of integrin function. J. Biol. Chem. 271, 20365-20374 (1996).

35. Mould, A. P. et al. Defining the topology of integrin alpha5betal-fibronectin interactions using inhibitory anti-alpha5 and anti-betal monoclonal antibodies. Evidence that the synergy sequence of fibronectin is recognized by the aminoterminal repeats of the alpha5 subunit. J. Biol. Chem. 272, 17283-17292 (1997)

36. Preissner, K. T. Structure and biological role of vitronectin. Annu. Rev. Cell Biol. 7, 275-310 (1991).

37. Deng, G., Curriden, S. A., Hu, G., Czekay, R. P. \& Loskutoff, D. J. Plasminogen activator inhibitor-1 regulates cell adhesion by binding to the somatomedin $\mathrm{B}$ domain of vitronectin. J. Cell Physiol. 189, 23-33 (2001).

38. Kaur, S., Fielding, A. B., Gassner, G., Carter, N. J. \& Royle, S. J. An unmet actin requirement explains the mitotic inhibition of clathrin-mediated endocytosis. Elife 3, e00829 (2014).

39. Masuda, H. T. et al. Coating extracellular matrix proteins on a (3-aminopropyl) triethoxysilane-treated glass substrate for improved cell culture. Biotechniques 56, 172-179 (2014).

40. Gavard, J. et al. Lamellipodium extension and cadherin adhesion: two cell responses to cadherin activation relying on distinct signalling pathways. J. Cell Sci. 117, 257-270 (2004)

41. Kovacs, E. M., Ali, R. G., McCormack, A. J. \& Yap, A. S. E-cadherin homophilic ligation directly signals through Rac and phosphatidylinositol 3-kinase to regulate adhesive contacts. J. Biol. Chem. 277, 6708-6718 (2002)

42. Winklbauer, R. Cadherin function during Xenopus gastrulation. Subcell Biochem. 60, 301-320 (2012)

43. Marsden, M. \& DeSimone, D. W. Integrin-ECM interactions regulate cadherin dependent cell adhesion and are required for convergent extension in Xenopus. Curr. Biol. 13, 1182-1191 (2003).

44. Kaushik, R., Yu, F., Chia, W., Yang, X. \& Bahri, S. Subcellular localization of LGN during mitosis: evidence for its cortical localization in mitotic cell culture systems and its requirement for normal cell cycle progression. Mol. Biol. Cell 14, 3144-3155 (2003).

45. Seldin, L., Poulson, N. D., Foote, H. P. \& Lechler, T. NuMA localization, stability, and function in spindle orientation involve 4.1 and Cdk1 interactions. Mol. Biol. Cell 24, 3651-3662 (2013).

46. Byron, A. et al. A proteomic approach reveals integrin activation statedependent control of microtubule cortical targeting. Nat. Commun. 6, 6135 (2015).

47. Ballestrem, C. et al. Molecular mapping of tyrosine-phosphorylated proteins in focal adhesions using fluorescence resonance energy transfer. J. Cell Sci. 119, 866-875 (2006).

48. Polte, T. R. \& Hanks, S. K. Interaction between focal adhesion kinase and Crk-associated tyrosine kinase substrate p130Cas. Proc. Natl. Acad. Sci. USA 92, 10678-10682 (1995).

49. Harte, M. T., Hildebrand, J. D., Burnham, M. R., Bouton, A. H. \& Parsons, J. T. p130Cas, a substrate associated with $\mathrm{v}$-Src and $\mathrm{v}$-Crk, localizes to focal adhesions and binds to focal adhesion kinase. J. Biol. Chem. 271, 13649-13655 (1996).

50. Nakamoto, T., Sakai, R., Ozawa, K., Yazaki, Y. \& Hirai, H. Direct binding of C-terminal region of p130Cas to $\mathrm{SH} 2$ and $\mathrm{SH} 3$ domains of Src kinase. J. Biol. Chem. 271, 8959-8965 (1996).

51. Pellicena, P. \& Miller, W. T. Processive phosphorylation of p130Cas by Src depends on SH3-polyproline interactions. J. Biol. Chem. 276, 28190-28196 (2001).

52. Ilic, D. et al. Reduced cell motility and enhanced focal adhesion contact formation in cells from FAK-deficient mice. Nature 377, 539-544 (1995)

53. Honda, H. et al. Cardiovascular anomaly, impaired actin bundling and resistance to Src-induced transformation in mice lacking p130Cas. Nat. Genet 19, 361-365 (1998).

54. Sawada, Y. et al. Force sensing by mechanical extension of the Src family kinase substrate p130Cas. Cell 127, 1015-1026 (2006).

55. Fonseca, P. M. et al. Regulation and localization of CAS substrate domain tyrosine phosphorylation. Cell Signal. 16, 621-629 (2004)

56. Meenderink, L. M. et al. P130Cas Src-binding and substrate domains have distinct roles in sustaining focal adhesion disassembly and promoting cell migration. PLoS ONE 5, e13412 (2010).

57. Thomas, J. W. et al. SH2- and SH3-mediated interactions between focal adhesion kinase and Src. J. Biol. Chem. 273, 577-583 (1998). 
58. Ruest, P. J., Shin, N. Y., Polte, T. R., Zhang, X. \& Hanks, S. K. Mechanisms of CAS substrate domain tyrosine phosphorylation by FAK and Src. Mol. Cell Biol. 21, 7641-7652 (2001).

59. Bodary, S. C. \& McLean, J. W. The integrin beta 1 subunit associates with the vitronectin receptor alpha $\mathrm{v}$ subunit to form a novel vitronectin receptor in a human embryonic kidney cell line. J. Biol. Chem. 265, 5938-5941 (1990).

60. Whittard, J. D. et al. E-cadherin is a ligand for integrin alpha2beta1. Matrix Biol. 21, 525-532 (2002).

61. Kwon, M., Bagonis, M., Danuser, G. \& Pellman, D. Direct microtubule-binding by myosin-10 orients centrosomes toward retraction fibers and subcortical actin clouds. Dev. Cell 34, 323-337 (2015).

62. Rivera, G. M. et al. Requirement of Nck adaptors for actin dynamics and cell migration stimulated by platelet-derived growth factor B. Proc. Natl. Acad. Sci. USA 103, 9536-9541 (2006).

63. Sharma, A. \& Mayer, B. J. Phosphorylation of p130Cas initiates Rac activation and membrane ruffling. BMC Cell Biol 9, 50 (2008).

64. Halet, G. \& Carroll, J. Rac activity is polarized and regulates meiotic spindle stability and anchoring in mammalian oocytes. Dev. Cell 12, 309-317 (2007).

65. Ezratty, E. J., Partridge, M. A. \& Gundersen, G. G. Microtubule-induced focal adhesion disassembly is mediated by dynamin and focal adhesion kinase. Nat. Cell Biol. 7, 581-590 (2005).

66. Kiyomitsu, T. \& Cheeseman, I. M. Chromosome- and spindle-pole-derived signals generate an intrinsic code for spindle position and orientation. Nat. Cell Biol. 14, 311-317 (2012).

\section{Acknowledgements}

We thank Drs Chenbei Chang, Fumiko Toyoshima, Douglas DeSimone, John Wallingford, Steven Hanks and Sara Cabodi for providing plasmids, antibodies and cell lines. We thank Dr Vasilis Promponas for his guidance with the statistical analysis of the results. Funding was provided by the Cyprus Research Promotion foundation and by the structural funds of the European Union TEXNO $\Lambda$ ОГIA/ $\Lambda$ IKA/0311(BIE).

\section{Author contributions}

N.I.P. performed the experiments, N.I.P and P.A.S. designed the experiments, analysed the data and wrote the manuscript.

\section{Additional information}

Supplementary Information accompanies this paper at http://www.nature.com/ naturecommunications

Competing financial interests: The authors declare no competing financial interests.

Reprints and permission information is available online at http://npg.nature.com/ reprintsandpermissions/

How to cite this article: Petridou, N. I. et al. A ligand-independent integrin $\beta 1$ mechanosensory complex guides spindle orientation. Nat. Commun. 7:10899 doi: 10.1038/ncomms10899 (2016).

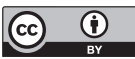

This work is licensed under a Creative Commons Attribution 4.0 International License. The images or other third party material in this article are included in the article's Creative Commons license, unless indicated otherwise in the credit line; if the material is not included under the Creative Commons license, users will need to obtain permission from the license holder to reproduce the material. To view a copy of this license, visit http://creativecommons.org/licenses/by/4.0/ 